\title{
GAPS, GHOSTS AND GAPLESS RELATIVES IN SPOKEN ENGLISH ${ }^{1}$
}

Chris Collins, New York University

Andrew Radford, University of Essex

\begin{abstract}
This paper looks at the syntax of so-called gapless relative clauses in spoken English. §1 contrasts gap relatives (like that italicised in 'something which I said', in which there is a gap internally within the relative clause associated with the relativized constituent) with gapless relatives (like that italicised in 'They were clowning around, which I didn't really care until I found out they had lost my file', in which there is no apparent gap within the relative clause). In §2, we note that a number of recent analyses take which to function as a subordinating conjunction in gapless relatives, but we argue against this view and provide evidence that the wh-word in such clauses is indeed a relative pronoun. In §3, we argue that the relative pronoun in gapless relatives serves as the object of a 'silent' preposition. In $\S 4$, we present an analysis under which a preposition can be silent when it (or its containing PP) undergoes a type of deletion operation called Ghosting. §5 shows how Ghosting (like other deletion operations) can serve to rescue structures which would otherwise induce constraint violations. $\S 6$ discusses gapless relatives which have a Topic-Comment interpretation, and argues for an extended Ghosting analysis under which a predicate of SAYING associated with the ghosted preposition is also ghosted. Our overall conclusion is that supposedly 'gapless' relatives are more properly analysed as containing a gap created by relativization of the object of a ghosted preposition.
\end{abstract}

\section{Introduction}

Relative clauses in English typically involve a gap internally within the relative clause in a position associated with the relativized constituent - as illustrated by the bracketed restrictive relatives below (where --- marks a gap):

(1) a. the picture [which Bill saw ---]

b. the picture [that Bill saw ---]

c. the picture [Bill saw ---]

In WH RELATIVES like (1a), the relative clause is introduced by a WH constituent; in COMP RELATIVES like (1b), the relative clause is introduced by a complementiser like that; and in ZERO RELATIVES like (1c), there is no overt WH constituent or complementiser introducing the relative clause. Under movement-based accounts of the syntax of relative clauses, the gap in the relative clause arises via movement of a constituent which originates in the position marked by the gap and moves to the edge of the bracketed relative clause. Under the WH-MOVEMENT analysis of Chomsky (1977), the moved constituent is a wh-operator (overt in the case of 1a, and null in the case of 1b,c) which moves to the edge of CP, so that (1a) has a structure like (2a) below; on the alternative ANTECEDENT RAISING analysis of Kayne (1994), it is the antecedent picture which moves to the edge of CP, so that (1b) has a structure like that shown in (2b):

(2) a. [DP [D the] [NP [N picture] [CP which [C ø] Bill saw ----]]]

b. [DP [D the] [CP picture [C that] Bill saw ---]]

In either case, movement of the italicised constituent leaves a gap behind in the relative clause. 
Alongside gap relatives, spoken English also has gapless relatives (i.e. structures in which there appears to be no gap within the relative clause associated with the relativized constituent). Gapless appositive relatives have been discussed (among others) by Kjellmer (1988, 2010), Miller (1988, 1993), Kuha (1994) and Loock (2005, 2007, 2010). Illustrative examples of such clauses cited by the linguists in question are bracketed below:

(3) a. And I have to stay on to May, [which when I'm 16 in March I could be looking for a job] (Miller 1993)

b. She gained a half pound, [which they were predicting she'd gain five pounds] (Kuha 1994)

c. And she decided to move out, [which I think she's crazy] (Loock 2007) The appositive relative clauses introduced by which in sentences like (3) are gapless in the sense that which is not associated with any obvious gap in the clause (e.g. there appears to be no subject, object or adjunct gap in the wh-clause which could have arisen by moving which out of the gap position to the front of the relative clause). However, we argue in this paper that so-called gapless relative clauses involve a relative pronoun used as the object of a 'silent' preposition which undergoes a specific type of deletion operation termed Ghosting and we show that the Ghosting analysis is superior to alternative analyses of gapless relatives. The illustrative examples we use (unless otherwise specified) come from a corpus collected by Anonymous of non-canonical clause structures found in recordings of live, unscripted British radio and TV broadcasts: we will refer to this as the British Broadcast English/BBE corpus ${ }^{3}$. We begin (in the next section) by outlining (and arguing against) an analysis which claims that which in gapless appositives has become grammaticalised as a conjunction or connective.

\section{A conjunction analysis}

Miller (1993), Kuha (1994) and Loock (2005, 2007, 2010) all argue that which in gapless relative clauses like those in (3) has lost its status as a relative pronoun in present-day English and instead become grammaticalised as a subordinating conjunction like although - a claim which is far from implausible in principle, given that van Gelderen (2009) has documented cases of re-analysis of pronouns as conjunctions in a wide range of languages. More specifically, Miller (1993, p.113) claims that (in gapless appositives) which "is not a relative pronoun tying a relative clause to a particular noun but functions to signal a connection between the preceding chunk of text and the following one.” Noting that relative that was originally a pronoun and subsequently became reanalysed as a conjunction, he comments in relation to sentences like (3a) that 'It seems as though which is following the same path' (the apparent implication being that which functions as a conjunction in this use). Likewise, Kuha (1994: 1) argues that gapless relatives are used by a wide variety of (both British and American) speakers from differing backgrounds and age groups. She further claims (1994: 3) that 'This which does not carry out the function of a relative pronoun' and instead categorises it as a connective, drawing parallels with uses of the (subordinating) conjunction because. In a similar vein, Loock (2007:75) claims that gapless Appositive Relative Clauses/ARCs introduced by which are not relative clauses because 'No gap is apparent in the ARC and also, no antecedent seems to be systematically retrievable for the relative'. He concludes that which in gapless relatives is a simple connective (i.e. a conjunction). 
A key claim underpinning Loock's analysis of which as a conjunction (made explicit in the quotation at the end of the previous paragraph) is that which cannot be a relative pronoun in gapless relatives because it has no antecedent in such structures. Against this, however, it can be countered that the preceding clause is the antecedent of which in sentences like (3) - e.g. She decided to move out is the antecedent of which in (3c). Further evidence that which does indeed have an antecedent in gapless appositives comes from the observation that (as examples like those below illustrate), sometimes which has an (italicised) nominal antecedent:

(4) a. The right deal here (which I'm just thinking about conservative voters) isn't for Labour to get into bed with the Lib Dems (Tony Livesey, BBC Radio 5)

b. Let's talk about the economy, which we're all going to be paying back taxes for God knows how long (Ian Collins, Talk Sport Radio)

c. Then you've got your right side, which I think Aaron Lennon coming back against Man United was a good sign for England (Perry Groves, BBC Radio 5)

d. All we've had so far are words, which frankly we need to see the numbers (Economics reporter, BBC Radio 5)

e. We want reaction from the Southampton dressing-room, which the door remains firmly shut (Keith Hill, BBC Radio 5)

f. There's always the Landon Donovan approach, which Landon Donovan said: "You know what, I make plenty of money, I'm happier playing for Major League Soccer" (Sean Wheelock, BBC Radio 5)

g. There's also the stunning crash on the Tour de France, which I watched the highlights last night and I was amazed at what happened (Adrian Durham, Talk Sport Radio)

h. Look at the passes (724 against 199), which Arsenal are generally known as a passing team (Terry Gibson, Sky Sports TV)

i. Neighbours have described $a$ horrendous fire, which even though the fire engine arrived within three minutes, the two children still died (Reporter, BBC Radio 5)

Furthermore, which is not the only wh-pronoun used in gapless appositives. As the examples below illustrate, who also occurs in gapless appositives:

(5) a. They're complaining to the referee about Cristiano Ronaldo, who possibly it was a foul on Gonzalez (Terry Gibson, Sky Sports TV)

b. He was tackled by Vincent Kompany, who it was a bit of a rash challenge, but it was a decent one (Craig Burley, BBC Radio 5)

c. Now it's 1-0 to Villa, who we've just been saying it's a goal against the run of play (Connor MacNamara, BBC Radio 5)

d. He lobbed the ball in for Lee, who I've gotta say it was an excellent finish (Listener, BBC Radio 5)

e. If there's no money available, then why not tell the fans, who some pay 5 or 6 grand for a season ticket]? (Alan Brazil, BBC Radio 5)

f. You take Theo Walcott off and replace him with Rosicky, who Walcott's a better player than Rosicky (Listener, Talk Sport Radio) 
g. The name that sticks out for me is Lee Clark, the former Huddersfield Town manager, who the eyebrows were raised when he lost that job in the first place (Colin Murray, BBC Radio 5)

The choice between which and who is determined by the gender properties of the (italicised) antecedent, with who being used where there is a human antecedent (like Cristiano Ronaldo in 5a) and which being used where there is a non-animate antecedent (either an inanimate nominal antecedent like the right deal in $4 \mathrm{a}$, or a genderless clausal antecedent like She decided to move out in 3c). This makes it clear that wh-words do indeed have potential (nominal or clausal) antecedents in gapless relatives, and thus makes it more plausible to suppose that they are relative pronouns.

Moreover, there is evidence against analysing the wh-word as a conjunction or connective. Recall that Loock (2007) suggests that which in gapless appositives like those in (3) serves the function of being a CONNECTIVE which "relates or links two clauses, one of which is subordinate to the other" (2007: 79). This suggests that which in gapless appositives is a subordinating conjunction in the relevant use ${ }^{4}$. On this view, which in a sentence such as:

(3) b. She gained a half pound, which they were predicting she'd gain five pounds (Kuha 1994)

would have much the same function as a subordinating conjunction like although, and would serve to link a subordinate clause introduced by which to a main clause.

However, there are at least four aspects of the subordinating conjunction analysis which are potentially problematic. Firstly (as illustrated below), the which-clause cannot be positioned in front of the main clause, even though this is possible with subordinate clauses introduced by a typical subordinating conjunction like although:

(6) a. She gained half a pound, which/although they were predicting she'd gain 5 pounds

b. Although/*Which they were predicting she'd gain 5 pounds, she gained half a pound Secondly (as illustrated below), which cannot be modified by the kind of adverbial (like even) which can be used to modify a subordinating conjunction:

(7) a. She gained a half pound, (even) though they were predicting she'd gain five pounds

b. She gained half a pound, (*even) which they were predicting she'd gain five pounds

c. He asked Mary, and (even) she didn't know the answer

d. He asked Mary, (*even) who didn't know the answer

As the examples in (7) illustrate, even can modify a subordinating conjunction like though or a non-relative pronoun like she but not a relative pronoun like who. The fact that even cannot modify which in a gapless relative like (7b) therefore suggests that which is a relative pronoun.

Thirdly, as noted earlier, the antecedent of which in sentences like those in (4) is nominal rather than clausal, thereby undermining any analysis of which as a conjunction linking two clauses. Fourthly, who is used in place of which when the antecedent is human (as illustrated in 5 above), and typical subordinating conjunctions in English are not gendersensitive in this way.

By contrast, the four properties noted in the previous paragraph can be given a straightforward characterisation if the wh-word in gapless appositives is treated as a relative pronoun. The fact that the which-clause follows the main clause in sentences like (6) 
follows from the relative pronoun analysis, in that appositive clauses cannot precede their antecedents. The fact that appositive which cannot be modified by an item such as even (which can nonetheless modify subordinating conjunctions like though/if/after etc.) can be accounted for if which in gapless appositives is a relative pronoun, since relative pronouns cannot be modified by such items (as we see from 7d). Likewise, the fact that the wh-word has a (nominal or clausal) antecedent in gapless appositives follows from its status as a relative pronoun. Furthermore, the gender-sensitivity of the wh-word (who being used when there is a human antecedent, which when there is not) can be treated as a lexical property of the individual relative pronoun in question.

A further piece of evidence in support of analysing gapless appositives as introduced by a relative pronoun rather than a subordinating conjunction is that gapless relatives are found not only in appositive clauses, but also in restrictive relatives like those below which are introduced by a (bold-printed) wh-pronoun:

(8) a. He's someone [who even my old gran can bat better] (Geoff Boycott, BBC Radio 5 Sports Extra)

b. He's a fellow [who it often seems that the glass is half empty] (Tim Vickery, BBC Radio 5)

c. West Brom had a couple of crosses [which the keeper looked a bit iffy] (Robbie Savage, BBC Radio 5)

d. One-nil is always a score [which you can get back in] (sc. 'into the game'; Robbie Savage, BBC Radio 5)

e. He crossed $a$ ball [which Sam Allardyce, he wasn't too happy with his defenders] (Danny Mills, BBC Radio 5)

Moreover, alongside gapless wh-restrictives like those above, we also find gapless restrictive relatives introduced by the finite complementiser that (as in 9a,b), or the infinitival complementiser for (as in 9c,d), or a null finite complementiser (as in 9d,e), or a null infinitival complementiser (as in 9f,g):

(9) a. There are a couple of guys [that, who knows, something might happen one day] (Web Mistress, Talk Sport Radio)

b. It was also a club [that we knew there was a problem] (Steve Claridge, BBC Radio 5)

c. This is a matter [for people to make their minds up] (Dave Watts, BBC Radio 5)

d. Chelsea's a very much more difficult club [for him to go] (Jason Burt, Talk Sport Radio)

e. This is something [I think we've spoken before on Up All Night] (Reporter, BBC Radio 5)

f. It's something [we are working with our suppliers] (Businessman, BBC Radio 5)

g. That's difficult [to make a judgment] (Civil servant, BBC Radio 5)

h. It's a chance to give the two big lads something [to go and attack you] (Davie Provan, Sky Sports TV)

Since this is precisely the range of complementisers found in gap-containing restrictive relatives, it strengthens the case for positing that gapless relatives are indeed relative clauses.

Moreover, the BBE corpus also contains gapless free relative clauses introduced by the free relative pronoun what, like those below: 
(10) a. [What we need to make sure] is that we don't get too hysterical (Labour party blogger, BBC Radio 5)

b. [What it's persuaded me] is that it's a lot more complicated (Listener, BBC Radio 5)

c. [What there was evidence tonight] was a desire to win (Mark Chapman, BBC Radio 5)

d. [What we're all waiting now] is the knock-on effect on Chelsea (Reporter, Sky Sports TV)

e. [What I would agree with the caller], though, is that in the modern game you can get two soft yellows (Darren Fletcher, BBC Radio 5)

f. [What he went wrong] was to come sliding in, in these conditions (Jimmy Armfield, BBC Radio 5)

The overall conclusion which such examples lead to is that gapless relatives occur in restrictive relatives, appositive relatives and free relatives alike, and that the wh-word in such structures is a relative pronoun (and not e.g. a conjunction).

Furthermore, just like typical relative pronouns, the wh-word in gapless relatives is positioned on the leftmost edge of the clause it introduces and so precedes other (italicised) peripheral constituents, which in turn precede the (underlined) subject - as illustrated below:

(11) a. He crossed a ball [which Sam Allardyce, he wasn't too happy with his defenders] (Danny Mills, BBC Radio = 8e)

b. The referee showed him a red card, [which what else could he have done in the circumstances?] (Alan Brazil, Talk Sport Radio)

c. I'm sure Harry will send Crouch and Keane out, [which if he gets money for either, the club will be very pleased] (Ian McGarry, BBC Radio 5)

d. He's a fabulous player [who, given the right conditions and the right management, we could be talking about one of the best players in the world] (Sid Lowe, Talk Sport Radio)

e. We played them once at Barbados, [which obviously we know what the Aussies are all about] (Stuart Broad, BBC Radio 5)

The wh-word precedes an (italicised) dislocated topic in (11a), a fronted interrogative whconstituent (and an inverted auxiliary) in (11b), and a variety of clausal or phrasal peripheral adjuncts in (11c-e). The position of the wh-word on the leftmost edge of the relative clause may reflect a requirement for a relative pronoun to be as close to its antecedent as possible (perhaps in order to facilitate antecedent identification). If we use the traditional label CP to denote the highest projection in the clause periphery, we can conclude that the wh-word is positioned on the edge of CP in gapless relatives ${ }^{6}$. But how does the wh-word come to be positioned on the outer periphery of the clause, and how is it linked to the inner core of the relative clause? In the next section, we provide a novel answer to this question.

\section{Silent prepositions}

An interesting property of gapless relative clauses is that they have a close paraphrase in which an (overt or null) wh-pronoun serves as the object of a preposition. For example, each of the bracketed gapless relative clauses in (12) below can be paraphrased as a 
structure containing a silent preposition (below enclosed in angle brackets, but not pronounced):

(12) a. When I went over there, they were clowning around, [which I didn't really care <about> until I found out they had lost my file] (unidentified American informant, Kuha 1994)

b. Laura Maxwell is with someone [who I think, Laura, that's happened $<$ to $>$ ] (Aasmah Mir, BBC Radio 5)

c. That's the situation [that Obama and to some extent the party find themselves $<$ in $>$ ] (American reporter, BBC Radio 5)

d. It was one [that the whole team played a big part <in>] (Mike Gatting, BBC Radio 5)

e. He's had a fine game, the Slovakian, for a Liverpool side [that Roy Hodgson has made 7 changes $<$ to $>$ ] (Darren Fletcher, BBC Radio 5)

f. It was also a club [that we knew there was a problem < with $>$ ] (Steve Claridge, BBC Radio 5)

h. The one [he got Strauss out < with>] was excellent (Geoff Boycott, BBC Radio 5 Sports Extra)

g. The penultimate game [that you took charge $<$ of $>$ at Chesterfield], you lost one-nil (Pat Murphy, BBC Radio 5)

There is evidence that the preposition must be present in the syntax of such sentences (albeit it is given a 'silent' pronunciation at PF). The evidence comes from the fact that non-wh counterparts of the relativized constituent require an (italicised) preposition to introduce them, as we see from:

(13) a. I didn't really care *(about) that

b. That's happened *(to) her

c. Obama and the party find themselves *(in) a difficult situation

d. The whole team played a big part *(in) that one

e. Roy Hodgson has made 7 changes *(to) the Liverpool side

f. There was a problem *(with) the club

g. He got Strauss out * (with) a bouncer

h. You took charge * $(o f)$ the game at Chesterfield

But if (as we claim) structures like those in (12) involve relativisation of the object of a preposition, how does the preposition come to be 'silent'?

One possible answer is suggested by work by Caponigro and Pearl $(2008,2010)$ on free relative clauses like those bracketed below in which an (italicised) wh-pronoun in a nominal position (serving as the direct object of a transitive verb) is associated with a PP gap inside the relative clause:

(14) a. Lily adores [where this very tree grows $<\mathrm{PP}>$ ]

b. Lily dreaded [when Jack had to go $<\mathrm{PP}>$ ]

c. Lily loathes [how all thieves work $<\mathrm{PP}>$ secretly]

Caponigro and Pearl justify the claim that the wh-pronoun is in an NP position and is associated with a PP gap (inter alia) by the observation that the relevant structure is paraphraseable as a relative clause structure containing a relativized prepositional object with a nominal antecedent (e.g. the where-clause in 14a is paraphraseable as 'the place in 
which this very tree grows'). The analysis they propose for 'silent preposition' structures like (14) claims that the wh-word originates as the object of a silent counterpart of the preposition in, and then the wh-word (which they take to be an NP) undergoes whmovement to spec-CP on its own, leaving the empty preposition stranded in situ. On this view, the bracketed relative clause in (14a) has the following superficial structure:

(15) Lily adores [ср where [с ø] this tree grows [рp [р ø] < where $>$ ]]

They further maintain that where/when/how can be used as the complement of a silent preposition not only in free relative clauses like those in (15), but also in interrogative clauses like (16a) below, which they take to have a structure like (16b):

(16)(a) Where did Lily sleep?

(b) [ср Where [c did] Lily sleep [рг [р ø] < where> ]]

They claim that (in such structures) where/when/how are base-generated as the complement of a preposition which can be silent when it has an interpretation which matches that of the wh-pronoun: consequently, a locative preposition can be silent when it has the locative complement where, a temporal preposition can be silent when it has the temporal complement when and a manner preposition can (and, they claim, must) be silent when it has the manner complement how.

They argue that their 'silent preposition' analysis gains independent motivation from the fact that the wh-word can serve as the object of a (bold-printed) overt preposition in a free relative clause such as that bracketed below:

(17) Jack disliked [where we just ran past < where > ] because it smelled funny The fact that where can serve as the object of an overt preposition like past in a structure like (17) adds plausibility to the claim that where can serve as the object of a silent preposition in a structure like (16b), they maintain. Moreover, they note that independent research by Emonds $(1976,1987)$ and McCawley (1988) has argued for the presence of a silent preposition in so-called adverbial NPs such as those italicised below:

(18) a. John arrived that day/Sunday/yesterday

b. You have lived there/few places that I like

c. You pronounced my name that way/every way one could imagine.

The italicised NP (they claim) serves as the complement of a preposition which is a silent counterpart of temporal on in (18a), of locative in in (18b), and of manner in in (18c).

Although Caponigro and Pearl do not discuss gapless relatives, their 'silent preposition' analysis of free relatives and adverbial NPs could potentially be extended to account for these if we were to posit that (in spoken English) a relative pronoun like which/who (or a null counterpart) can be used as the object of a silent preposition. If so, the relative clause bracketed in (12a) would have a structure along the following lines:

(19) [ср which [с ø] I didn’t really care [рP [р ø] < which>] until I found out...]

The relative pronoun which would originate as the complement of a silent counterpart of the preposition about in (19), and which would subsequently move to spec-CP on its own, leaving the silent preposition stranded.

However, there are a number of problems which would face the 'silent stranded preposition' analysis of gapless relatives sketched in (19). One such is interpretive in nature. In this respect, it should be noted that there is a clear interpretive asymmetry between the standard English ‘silent preposition' structures discussed by Caponigro and 
Pearl and their non-standard spoken English gapless relative counterparts discussed by us. In standard English 'silent preposition' structures, the preposition has a narrow range of (place/time/manner) interpretations, with the semantic properties of the preposition matching (and so being able to be inferred from) those of its complement - e.g. a silent preposition is interpreted as having a locative interpretation when it has a locative where complement in a structure like (15). This in effect means that a preposition can only be silent when its content can be inferred from its complement. However, no such matching effect holds between the preposition and its complement in gapless relative clauses like those in (19) and (12): e.g. which has no specific interpretive properties that would allow the null preposition in (19) to be interpreted as a null counterpart of about. Given that an unrestricted range of prepositions can be 'missing' in gapless relative, an analysis like that in (19) would seemingly require us to suppose that the missing preposition has a potentially unrestricted interpretation which cannot be inferred from the relative pronoun and which has instead to be inferred from syntactic, semantic and pragmatic clues: this would create a clear asymmetry with the silent preposition structure posited by Caponigro and Pearl in (14-18).

A second problem posed by the silent preposition analysis is distributional in nature. Silent prepositions in Caponigro and Pearl's analysis are said to occur in free relative clauses like (14), interrogatives like (16) and in situ adverbial nominals like (18) in standard varieties of English. However, the kind of non-standard 'missing' preposition structures which we are concerned with here are restricted to occurring in relative clauses in our recordings $(n=243)$, there being no clearcut interrogative examples ${ }^{7}$, and no in situ adverbial examples. Thus, there is a clear distributional asymmetry between the relatively wide range of contexts in which silent prepositions occur in standard varieties of English (relative clauses, interrogative clauses, and in situ adverbials) and the much narrower range of contexts (only relative clauses) in which prepositions can be silent in non-standard varieties of spoken English. The analysis which we will develop in the next section accounts for this distributional asymmetry, but we see no principled way of accounting for it in terms of the kind of silent preposition structure posited by Caponigro and Pearl.

A third problem posed by the silent preposition analysis relates to the fact that a core assumption of Caponigro and Pearl's analysis which they make explicit (2008:5 and 2010: 159; fn.3) is that 'silent Ps are always stranded' when they have a wh-object.

However, our recordings contain relative clauses such as the (a) examples in (20-25) below in which unstrandable prepositions are silent, as we see from the paraphrases of the relative clauses in the corresponding (b, c) examples:

(20) a. If we don't get rain in the next week, then water levels will have reached the point [that we will need to impose a hose-pipe ban] (Water company spokesman, BBC Radio 5)

b. ...the point [at which we will need to impose a hose-pipe ban]

c. ...*the point [which we will need to impose a hose-pipe ban at

(21) a. Manchester United have got a good goalkeeper, [which Torres could've had a goal] (Peter Allen, BBC Radio 5)

b. ... [without which Torres could've had a goal]

c. ...*[which Torres could've had a goal without]

(22) a. We didn't get the standards physically, [which obviously we've lost the game] 
(Steve Bruce, BBC Radio 5)

b. ... [because of which obviously we've lost the game]

c. ...*[which obviously we've lost the game because of]

(23) a. There's always the Landon Donovan approach, [which Landon Donovan said: "You know what, I make plenty of money, I'm happier playing for Major League

Soccer"] (Gary Richardson, BBC Radio $5=4$ f)

b. ... [in which Landon Donovan said "You know what, ..."]

c. ...*[which Landon Donovan said in "You know what, ..."]

(24) a. It's an environment [that people are trying to get better] (Gabby Logan, BBC Radio 5)

b. ... [in which people are trying to get better]

c. ...*[which people are trying to get better in]

(25) a. Players need to play on a level [which you know what you're going to get out of them] (Ray Parlour, Talk Sport Radio)

b. ... [at which you know what you are going to get out of them]

c. ...*[which you know what you're going to get of them at]

The fact that the (a) examples only allow a paraphrase with a pied-piped preposition (and not one with a stranded preposition) calls into question Caponigro and Pearl's central assumption that prepositions with wh-objects can only be silent when stranded.

Having examined (and argued against) the possibility that gapless relatives involve relativisation of the object of a silent stranded preposition, we now turn to develop a novel deletion analysis in the next section.

\section{Ghosting}

An alternative to a silent preposition analysis of missing prepositions in gapless relatives is to suppose that prepositions go missing via a deletion operation of some kind. One way in which prepositions can be deleted is via Ellipsis. In this connection, consider how the angle-bracketed preposition comes to be 'silent' in the following:

(26) a. The fact that it was against the opposition [that it was <against>], does that make it even more special? (Interviewer, Sky Sports TV)

b. That's why I'm in the position [I am <in>] (Mark Webber, BBC Radio 5)

c. The teams are in the colours [you'd expect them to be $<$ in $>$ ] (Nigel Adderley, BBC Radio 5)

The reason why the preposition inside the bracketed relative clause is unpronounced is that it undergoes the same form of Ellipsis (involving Antecedent-Contained Deletion) as that which results in the angle-bracketed verb phrase being elided in sentences such as the following:

(27) The fact that you were playing against the opposition [that you were < playing against>], does that make it feel even more special?

This raises the question of whether all 'silent' prepositions in gapless relatives can be taken to be the result of Ellipsis.

The answer is 'No', for the following reason. Cases of Ellipsis involve a constituent being given a null spellout when it has an antecedent. However, only 19/243 (8\%) of the gapless relatives in our recordings were structures like (23) where the 'missing' preposition in the relative clause had an antecedent in the matrix clause; the overwhelming majority of 
gapless relatives with 'missing' prepositions in our recordings $(224 / 243=92 \%)$ were antecedentless. How do such structures come about? What we shall argue in this section is that they are the result of a different type of deletion operation which Collins and Postal (2012) term Ghosting. They argue for the need to distinguish ellipsis (i.e., deletion linked to the need for some type of antecedent) from what we will call ghosting. The latter term will denote the grammatical deletion of elements whose deletion does not depend on the existence of any antecedent phrase

[Collins and Postal, 2012: 32]

In this section, we argue that gapless relatives containing missing antecedentless prepositions arise when a preposition or prepositional phrase undergoes Ghosting.

As already noted, an interesting property of the kind of preposition ghosting found in our recording is that it occurs only in structures in which the object of the preposition undergoes wh-movement, and not in structures in which the prepositional object remains in situ. So, for example, we have no examples of structures like those in (13) in which an italicised in situ preposition undergoes Ghosting (as we see from the ungrammaticality of ghosting about in 13 a *I didn't really care <about> that). This observation suggests possible parallels with structures such as the following (discussed by Kayne 2005 and Collins 2007), in which an italicised preposition which can be overt in (28) is obligatorily silent when it undergoes WH-MOVEMENT in (29):

(28) a. Where did you go (to)?

b. Where is he staying (at)?

(29) a. (*To) where did he go?

b. $(* A t)$ where is he staying?

Collins (2007) accounts for the pattern in (28-29) as follows. Following Katz and Postal (1964: 128, 135) he posits that English $r$-pronouns (like here, there and where) are the objects of the prepositions to/at in sentences like (28-29). Following van Riemsdijk (1978: 41; 87), Collins further claims (2007: 4) that ' $r$-pronouns obligatorily move to the specifier of TO/AT in English', by an operation which we will call Prepositional Inversion (because it inverts the order of the preposition and its object) ${ }^{8}$. This results in the structure below (in which where moves from being the complement to becoming the specifier of the preposition to/at):

(30) $\quad[\mathrm{pp}$ where $[\mathrm{p}$ to/at $]<$ where $>]$

Following Koopman (2000) and Koopman and Szabolsci (2000), Collins posits that a structure like (30) violates a generalised version of the Doubly Filled COMP Filter of Chomsky and Lasnik (1977), which can be given the following formulation for present purposes (differing in inessential ways from Collins 2007):

(31) Edge Constraint

No more than one position on the edge of a phase can be filled by an overt constituent

(Collins takes phases to include CP, vP, PP and DP). The Edge Constraint accounts (inter alia) for why relative clauses cannot contain both an overt wh-word and an overt complementiser in structures such as:

(32) *It was a film [ср which [C that] I enjoyed watching] 
Returning now to our earlier PP structure in (30), it should be clear that if nothing else happens, the Edge Constraint (31) will rule out the PP in (30) as ill-formed because it has an overt head to/at and an overt specifier where.

One way of 'rescuing' (30) is for where to undergo WH-MOVEMENT on its own, resulting in the structure (33) below (cf. Collins 2007:6;19b), if we take where to be a DP, and assume that where transits through spec-PP on its way to spec-CP (because PPs are phases):

[DP where] is he staying [PP $<\mathrm{DP}>[\mathrm{p}$ at $]<\mathrm{DP}>$ ]]

Since the preposition at is the only overt constituent on the edge of the PP in (33), there is no violation of the Edge Constraint, and the resulting structure in which the preposition at is stranded in situ is grammatical.

However, since prepositions can be pied-piped when their objects are wh-moved, an alternative possibility is for the whole PP in (30) to undergo WH-MOVEMENT, so resulting in the following structure (cf. Collins: 2007:6;19a):

(34) [pp where $[\mathrm{p}$ at $]<$ where $>$ ] is he staying $<\mathrm{PP}>$

A structure like (34) fall fouls of the Edge Constraint (31), since the fronted PP has both an overt (italicised) specifier and an overt (bold-printed) head. In such cases, violation of the constraint is obviated by ghosting the preposition to, so mapping (34) into:

(35) $\quad[$ pP where $[\mathrm{p}<$ at $>$ ] $<$ where $>$ ] is he staying $<$ PP $>$

Since the only overt constituent in the fronted PP is the wh-word where, there is no Edge Constraint violation in (35). On this view, Preposition Ghosting in structures like (35) serves to obviate violation of the Edge Constraint, in the sense that a preposition is ghosted in a structure which would otherwise violate the Edge Constraint (i.e. a preposition is ghosted when it has an overt specifier).

An interesting question which arises from the discussion above is whether we can deal with gapless relative clauses like those in (12) above in spoken English by extending the Preposition Ghosting analysis sketched above from $r$-pronouns like where to other relative pronouns like who/which, and from the prepositions to/at to other prepositions. We could then suppose that (in spoken English) Preposition Ghosting would also apply (inter alia) in structures such as the following:

(12) a. When I went over there, they were clowning around, [which I didn't really care $<$ about> until I found out they had lost my file] (unidentified American informant, Kuha 1994)

b. Laura Maxwell is with someone [who I think, Laura, that's happened <to>] (Aasmah Mir, BBC Radio 5)

Pursuing this possibility, let us suppose that which undergoes Prepositional Inversion and moves to become the specifier of about in (12a), so deriving:

(36) [pp which [p about] < which $>$ ]

If which moves on its own to spec-CP and if $\mathrm{C}$ in finite declarative clauses is lexicalised as that, we derive the following structure:

(37) [CP which [C that] I didn't really care [PP < which $>$ [p about] < which $>$ ] until...] The CP in (37) violates the Edge Constraint (since it has an overt head and an overt specifier), but can be rescued by Ghosting that, resulting in the structure below: 
(38) [CP which [C <that >] I didn't really care [PP < which $>$ [P about] < which $>$ ] until...] (38) incurs no violation of the Edge Constraint (31) since the edge of CP contains only one overt constituent (= which), and the edge of PP likewise contains only one overt constituent (= about).

An alternative possibility is for the whole PP in (36) to undergo WH-MOVEMENT, resulting in the structure below:

(39) [CP [pp which [p about] <which $>$ ] [c that] I didn't really care $<\mathrm{PP}>\ldots$...

There is a double violation of the Edge Constraint in (39), since both CP and the fronted PP have an overt head and specifier. However, this double violation can be rescued by Ghosting both the head P of PP and the head C of CP, so mapping (39) into:

(40) [CP [pP which [p $<$ about $>]<$ which $>$ ] [c $<$ that $>$ ] I didn't really care $<$ PP $>\ldots$. $]$ The resulting structure (40) no longer violates the Edge Constraint, since the fronted PP has an overt specifier which but a null head, and CP has an overt specifier (a PP containing which) and a null head. As should be obvious, the analysis sketched here can be generalised from gapless which-relatives like (12a) to gapless who-relatives like (12b).

Now consider how to deal with preposition ghosting in gapless relatives introduced by the complementiser that, such as:

(12) e. He's had a fine game, the Slovakian, for a Liverpool side that Roy Hodgson has made 7 changes $<$ to $>$ (Darren Fletcher, BBC Radio 5)

Let us suppose that the relative pronoun which is the object of the preposition to in (12e). If which undergoes Prepositional Inversion and raises to become the specifier of to and the resulting PP undergoes WH-MOVEMENT to spec-CP, we derive:

(41) [CP [pp which [p to] < which $>$ ] [c that] Roy Hodgson has made 7 changes $<\mathrm{PP}>$ ] There is a double violation of the Edge Constraint in (41), since both CP and the fronted PP have an overt head and an overt specifier. One way in which (41) can be rescued is by ghosting the whole PP containing which and to, so deriving the following:

(42) $\left[{ }_{\mathrm{CP}}[\mathrm{pP}<\right.$ which $>[\mathrm{P}<$ to $>$ ] $<$ which $>$ ] [C that] Roy Hodgson has made 7 changes $<\mathrm{PP}>$ ] Neither CP nor PP in (42) violates the Edge Constraint, so in this case Ghosting obviates a potential double violation of the Edge Constraint, and derives the structure associated with the italicised relative clause in (12e).

Finally, consider the derivation of gapless ZERO relatives like that italicised in:

(12) g. It's one of those games the Scotland players will raise their game <in> (John Collins, BBC Radio 5)

Let's suppose that the relative clause in (12g) contains a relative pronoun which serving as the object of the preposition in, and that which is raised by Prepositional Inversion to become the specifier of in, resulting in the PP [pp which [p in] < which>]. If which then moves to spec-CP on its own, it will leave the preposition in stranded in situ, and the preposition will be spelled out overtly on our assumptions. But if the preposition is piedpiped along with which and the whole PP moves to spec-CP, we derive the following structure instead:

(43) $\quad[\mathrm{cp}[\mathrm{pp}$ which $[\mathrm{p}$ in $]<$ which $>]$ [c that $]$ the Scotland players will raise their game $<\mathrm{PP}>$ ]

The resulting structure induces a double violation of the Edge Constraint, since both CP and PP have an overt head and an overt specifier. However, there are several ways in which Ghosting can rescue the structure in (43). 
One is for in to be ghosted in order to avoid a PP with an overt head and specifier, and for that also to be ghosted in order to avoid a CP with an overt head and specifier: this would derive a silent preposition structure like (40). A second is for the whole PP [PP which [P in] < which $>$ ] to be ghosted, resulting in a that-clause structure with a silent preposition like (42). A third is for both the PP specifier and the complementiser that to be ghosted, so deriving the structure shown in simplified form below:

(44) $\left[{ }_{\mathrm{CP}}[\mathrm{PP}<\right.$ which $>[\mathrm{P}<\mathrm{in}>]<$ which $>]\left[{ }_{\mathrm{C}}<\right.$ that $\left.>\right]$ the Scotland players will raise

(44) is then the superficial structure of the italicised relative clause in (12g) ${ }^{9}$. their game $<\mathrm{PP}>$ ]

The Ghosting analysis outlined here proves superior to the silent stranded preposition analysis sketched in the previous section in respect of overcoming all three problems which beset that analysis, viz. (i) the interpretive problem, (ii) the distributional problem, and (iii) the stranding problem. The interpretive asymmetry between 'silent prepositions' in standard English (which are restricted to having a place/time/manner interpretation) and ghosted prepositions in spoken English (which can have an unrestricted interpretation) can be accounted for by positing that ghosted prepositions have an unrestricted range of possible interpretations precisely because any preposition can be ghosted. The Ghosting analysis also provides a principled account of distributional differences between ghosted prepositions in spoken English (which occur only in relative clauses) and silent prepositions in standard English (which occur in relatives, interrogatives and adverbial NPs) by positing that Ghosting only occurs with relative pronouns in spoken English because these are 'light' constituents which have developed caseless variants (see below for a fuller account). Finally, the Ghosting analysis also accounts for why prepositions which can't be stranded can nonetheless be ghosted by positing that ghosted prepositions undergo pied-piping ${ }^{10}$.

Since gapless relatives are characteristic of spoken rather than written English, an important question arising from our analysis is what differences exist between spoken and written English which allow prepositional constituents to be ghosted in informal registers of spoken English but not in formal registers of written English. In this connection, it should be noted that Collins (2007) suggests that only light nouns (i.e. 'defective' nouns with limited semantic and grammatical content) can land in spec-PP by Prepositional Inversion and trigger Preposition Ghosting, whereas other constituents can only transit through spec-PP (when being extracted out of PP). Collins also argues (2007: 19) that the noun home in expressions like He stayed home is a light noun which originates as the complement of the preposition at, but thereafter moves to become the specifier of at, so forming the structure [рp home [p at] <home $>$ ]; subsequent Ghosting of at derives the structure [pp home $[\mathrm{p}<\mathrm{at}>$ ] $<$ home $>$ ]. He further suggests (ibid.) that light nouns like home lack case, and that the preposition at in such structures 'checks no case feature' (Collins, 2007: 19). He claims that that $r$-pronouns incorporate the light noun PLACE (so that where has a more abstract structure paraphraseable as WHAT PLACE), and notes that expressions incorporating the light noun PLACE allow Inversion and Ghosting (as in 'We went someplace different'), although he concedes (2007: 11) that 'I do not have any answer at this point to the deeper question of what drives movement of light noun place/PLACE (including the $r$-pronouns) into Spec P'. 
However, it may be that we can develop an answer along the following lines. Let us suppose that UG incorporates the following constraint:

(45)

\section{Case Constraint}

A caseless constituent cannot occur in a case position (in the c-command domain of a case assigner)

Such a constraint gains empirical motivation from the fact that the complementiser that (which Safir 1986 argues to be caseless) cannot occur in the domain of a transitive preposition like of - as we see from:

(46) I'm convinced of his remorse, but not convinced (*of) that he should be freed It will then follow that movement of a caseless light noun from being the complement of a preposition to becoming its specifier provides a way of avoiding violation of the Case Constraint (45). Let us further suppose that a caseless light noun is frozen in place once it moves to spec-PP: we can suppose that this is because (in the same way as spec-FocP is the criterial position for a fronted focused constituent: Rizzi 1996), spec-PP is the criterial position for the caseless object of a preposition. If the light noun is frozen in place in specPP, any subsequent movement of the light noun will induce pied-piping of the whole PP. Why should a caseless light noun be frozen in place in spec-PP? The answer may lie in a constraint to the effect that the complement of a preposition can only be extracted out of a containing PP if it enters into a case/agreement relation with the preposition (so that the object of a preposition can only be extracted out of its containing PP if there is some morphological marking of the relation between the preposition and its object). Since, by hypothesis, caseless relative pronouns do not enter into any case/agreement relation with the relevant preposition, they cannot be extracted out of their containing PP.

Given this theoretical background, let us suppose that relative pronouns like which/who are 'light' (perhaps by virtue of having an antecedent from which their content is recoverable) and have developed caseless counterparts in spoken English. This letter assumption is plausible, given the attrition of case endings on relative pronouns in spoken English, with the archaic accusative form whom being defunct and whose relatives being supplanted by relatives like:

(47) Players like Fabio Cannavaro, who we know their quality, haven't been great this season (Alvin Martin, Talk Sport Radio)

(See Tottie 1997, Tagliamonte 2002, Britain 2008, and Cheshire, Adger and Fox 2010 for evidence that whom/whose are not used in contemporary colloquial English.) If colloquial English has developed caseless counterparts of which/who alongside their case-marked counterparts, the caseless variants will obligatorily move to spec-PP by Prepositional Inversion in order to be outside the case domain of the preposition (while still remaining inside the PP they serve as the object of). If (as suggested above) an inverted caseless object is frozen in place in spec-PP, it follows that if the wh-pronoun subsequently undergoes wh-movement, it will obligatorily pied-pipe the rest of the PP along with it. But if the overall PP undergoes wh-movement, then in order to avoid violation of the Edge Constraint, either P or PP has to undergo Ghosting (as seen earlier). By contrast, in more formal registers of English, a relative pronoun like who/which carries case, and remains within the case domain of P (and is case-marked by P) unless extracted out of PP by an operation like wh-movement. If extracted, the relative pronoun transits through the edge of $\mathrm{PP}$ on the way to its ultimate landing site, because PP is a phase. On this view, spec-PP is 
the ultimate landing site for caseless prepositional objects, but only an intermediate transit site for case-marked prepositional objects. In sum: formal registers of English have no caseless counterparts of which/who, and so don't allow gapless relatives with which/who; informal registers have both case-marked and caseless counterparts of which/who, and use of caseless relative pronouns gives rise to gapless relatives ${ }^{11}$.

A further difference is that formal registers only allow ghosting of the locative preposition to/at in wh-clauses like those in (28-29), whereas informal registers allow any preposition to be ghosted in gapless relatives. Why should this be? As noted earlier, Collins (2007) claims that movement to spec-PP is only possible for constituents which incorporate the light nouns PLACE and home, and it is natural to suppose that the only prepositions which these will only serve as the complement of are locative to/at. But in spoken registers, the pronoun "which" is a light noun that can move to spec-PP, and since "which" has no PLACE component in its meaning, it can occur as the object of an unrestricted range of prepositions.

\section{Predicate Ghosting}

Although the Prepositional Ghosting analysis outlined in the previous section provides a plausible account of the majority of cases of gapless relatives in the $B B E$ corpus, there remains a residue of 68/243 (28\%) of gapless relatives which have a Topic-Comment interpretation and which seemingly prove problematic for any account which assumes Ghosting of a P or PP alone. In this section, however, we show that such sentences can also be given a Ghosting analysis (although with more than just a single P or PP ghosted).

The kind of structures involved are the following:

(48) a. You take Theo Walcott off and replace him with Rosicky, who Walcott's a better player than Rosicky (Listener, Talk Sport Radio = 5f)

b. You look at some of the other papers, who it's not going to be just the 'News of The World' running dodgy practices (Reporter, Talk Sport Radio)

c. He's a fabulous player who, given the right conditions and the right management, we could be talking about one of the best players in the world (Sid Lowe, Talk Sport Radio = 11d)

d. This is something that when you're abroad, people are blown away by the level of interest in the lower leagues (Andy Brassell, BBC Radio 5)

e. He's got to stay free from injury, which he's had a horrible time at all the clubs he's been at (Andy Goldstein, Talk Sport Radio)

f. Look at the passes (724 against 199), which Arsenal are generally known as a passing team (Terry Gibson, Sky Sports TV)

g. Jenson did get held up, which you never put your best lap in on your first lap (David Croft, BBC Radio 5)

i. All we've had so far are words, which frankly we need to see the numbers (Economics reporter, BBC Radio 5)

For such structures it would seem implausible to posit that all that has happened is that a preposition has been ghosted, since none of the angle-bracketed prepositions in (48) below provides an appropriate paraphrase of (48a):

(49) You take Theo Walcott off and replace him with Rosicky, who Walcott's a better player than Rosicky <*for/*with/*on/*by/*in/*at/*about> 
So how are we to deal with structures like those in (48)?

One possibility (which we will reject) would be to adopt a Topic-Comment analysis, under which the relative pronoun is directly merged on the edge of CP and serves to mark its antecedent as a Topic on which the rest of the relative clause makes a relevant Comment. On this view, the relative clause in (48a) would have a structure such as that shown in the second line of (50) below:

(50) You take Theo Walcott off and replace him with Rosicky,

[CP Who [С ø] [TP Walcott [T's] a better player than Rosicky]

The pronoun who would be base-generated on the edge of CP, and would be spelled out in the default form who (see Schütze 2001 on default forms). The relative clause would have a topic-comment interpretation loosely paraphraseable as 'about whom I would say that'.

Such a topic-comment analysis of gapless relatives is plausible in principle, since Chinese has gapless relative clauses and gapless topic structures (Zhang 2008), and the relation between the antecedent and the relative clause in gapless relatives has been argued by Tsai (1997) to be one of aboutness ${ }^{12}$. Under the Cartographic approach adopted in the works referred to in fn.6, the wh-pronoun could be taken to be base-generated in the specifier position of a Topic Phrase projection.

At first sight, the claim that (at least some) gapless relatives in English involve a gapless topic structure would appear to fall foul of the conventional wisdom that English (unlike Chinese) does not have gapless topic structures. However, this claim is undermined by the observation that the BBE corpus contains 58 examples of (potentially) gapless topic structures such as the following:

(51) a. England, I agree with you completely on Capello (Listener, BBC Radio 5)

b. Defoe, even I could have scored that goal (Alan Green, BBC Radio 5)

c. Temperatures, we are talking 13 to 15 Celsius (Aasmah Mir, BBC Radio 5)

d. An international manager's job, there is no pleasing anybody (Steve McClaren, BBC World Service)

e. A campaign like that, it's one thing to get people's attention and another to get things changed (Declan Curry, BBC Radio 5)

Such sentences contain a (bold-printed) topic followed by a gapless clause which makes a comment that is interpreted as being relevant to the topic, seemingly without any overt syntactic link between topic and comment.

However, a topic analysis of gapless relatives along the lines outlined in (50) above brings with it the evident disadvantage that it presupposes that pronouns like who and which have two entirely distinct uses: viz (i) an argumental use in which they are basegenerated as an argument of a preposition or verb and moved to the edge of CP, and (ii) a topical use on which they are base-generated in spec-CP and have a topic interpretation. Furthermore, if the topic has an aboutness function, topic structures are implicitly being treated as involving ghosting of a topic-marking preposition like about.

Let us therefore explore an alternative analysis for structures like those in (48) under which the relative clauses in question involve ghosting not only of a prepositional phrase headed by about, but also of parts of a clause containing a verb of SAYING. If we extend the Ghosting analysis in this way, the italicised relative clause in a sentence like (48b) would have a more elaborate ghost structure containing the 'silent' constituents 
contained within angle brackets below (an abstract counterpart of the structure found in sentences like 5c,d):

(52) You look at some of the other papers, who $<$ I would say about $>$ it's not going to be just the 'News of The World' running dodgy practices

On this view, Ghosting in (52) would affect all material between the bold-printed fronted wh-word and the italicised embedded clause but leave intact the matrix CP layer (containing who), along with the italicised embedded CP.

At first sight, any such Predicate Ghosting analysis might appear to be unprecedented and unmotivated. However, there are potential parallels here with Ross's (1970) analysis of root declarative clauses as containing an abstract verb of SAYING, under which a sentence like (53a) below would be derived from a structure like (53b), involving Ghosting of all constituents other than the embedded clause

(53) a. It is raining again

b. $<$ I say to you $>$ it is raining again

Thus, an analysis involving Predicate Ghosting is by no means unprecedented.

Furthermore, such an extended Ghosting analysis could be argued to gain independent motivation from sentences like:

(4) b. All we've had so far are words, which frankly we need to see the numbers (Economics reporter, BBC Radio 5)

The adverb frankly is typically construed with the external argument of a predicate of SAYING or THINKING (e.g. in 'Max says that frankly there is little hope of finding the hostages alive', it is Max who is being frank). If we suppose that the italicised relative clause in (4b) contains the ghost structure contained within angle brackets below:

(54) which $<$ I would say about $>$ frankly we need to see the numbers we can say that frankly is construed with $I$ (i.e. with the speaker) in (4b).

A second piece of evidence in support of the Predicate Ghosting analysis comes from sentences such as the following, in which the relative clause contains an (italicised) direct question (capitals in 55e marking contrastive stress):

(55) a. The referee showed him a red card, [which what else could he have done in the circumstances?] (Alan Brazil, Talk Sport Radio)

b. Then you launched these podcasts, [which how many times have these been downloaded?] (Richard Bacon, BBC Radio 5)

c. We're all humans living in a world [which what right does any country have to say "You can't come and live here"?] (Listener, BBC Radio 5)

d. Many students go to university and then have a gap year, [which by the way what's that supposed to be for?] (Ian Collins, Talk Sport Radio)

e. THERE's a man [that is he gonna get his first ever podium?] (Steve Parrish, BBC2 TV)

f. Then we had Steve McClaren, [who, do you know what the thing about Steve McClaren was?] (Steve Claridge, BBC Radio 5)

g. You're looking at a lad in Rio [who is he gonna be fit to play for England?] (Alan Mullery, Sky Sports TV)

h. And now it's hello to Graham Taylor, [who have you managed to lift your head after that six-nil defeat at St James's Park?] (Colin Murray, BBC Radio 5) 
The fact that Subject-Auxiliary Inversion/SAI takes place in italicised clause and that (in questions) SAI is found only in root clauses suggests that the italicised clause is a direct speech quotation. This in turn is consistent with the assumption that an abstract quotative predicate (like SAY or ASK) has been ghosted, with the result that the bracketed relative clause in (55a) has the structure shown below (where ghosted material is enclosed within angle brackets):

(56) [ср which [с ø] <I would say about> 'What else could he have done in the circumstances?']

Under the Predicate Ghosting analysis proposed here, the relative clause in (56) would have a structure parallel to that of the bracketed relative clauses in (57) below (with the anglebracketed preposition being ghosted):

(57) a. It's the one thing so far [that I would say <about> 'I'm not in agreement with what Capello has done'] (Graham Taylor, BBC Radio 5)

b. There's nothing [that you can say <about> 'This is Champions League football played at its best'] (Graham Taylor, BBC Radio 5)

c. They can produce things [that you go <about> 'Where did that come from?'] (Graham Taylor, BBC Radio 5)

d. He's the sort of player [that you might have said <about> 'Is he ever going to play for Australia again?’] (Simon Mann, BBC Radio 5 Sports Extra)

e. It's a car [which years from now you won't have to ask <about> 'What was I thinking?'] (American TV commercial, reported by Paul Postal pc)

The potential parallels include the use of an (italicised) direct quotation after the verb of saying. In most cases like (55a-g) and (57), the ghosted preposition is about; however, in (55h) it appears to be to (since the speaker is talking directly to Graham Taylor).

The overall conclusion to be drawn from this section is that gapless relatives which have a topic-comment interpretation can be handled by a plausible extension of the Ghosting analysis under which Ghosting affects not only a PP out of which a relativiser has been extracted, but also additional superordinate material containing the Predicate which selects the ghosted PP as an argument, so that when the preposition about is ghosted in (55), we find concomitant ghosting of all the material between the fronted wh-word (which) and the embedded clause ${ }^{13}$.

\section{Repair}

It has been widely reported in the research literature that certain types of deletion operation can be used to 'repair' (or 'rescue' or 'amnesty') potential constraint violations (see e.g. Ross 1969; Chomsky 1972; Lasnik 2001; Fox and Lasnik 2003; Hornstein, Lasnik, and Uriagereka 2003; van Craenenbroek 2004, 2010; Boeckx and Lasnik 2006; Merchant 2008; Nakao 2009; Bošković 2011; and Radford and Iwasaki 2012). It is therefore reasonable to maintain that the Ghosting analysis of gapless relatives would gain additional plausibility if Ghosting turned out to be able to serve a similar constraint repair function. And in this section, we shall argue that this is indeed the case.

In this connection, consider why the angle-bracketed preposition is ghosted in structures such as the following:

(58) a. He's a fellow [who it often seems <to > that the glass is half empty] (Tim Vickery, BBC Radio 5) 
b. This (= Frank Lampard) is a player [who you can't say <about $>$ that we've failed just because we've included Frank Lampard] (Adrian Durham, Talk Sport Radio) By hypothesis, such structures involve a relative wh-pronoun used as the complement of the capitalized ghosted preposition to/about. The resulting structures are ungrammatical if the capitalised preposition is not ghosted. Why should this be? The answer lies in a Preclausal Preposition Constraint/PPC which (in informal terms) bars a preposition from being stranded in front of a clause. PPC will account for contrasts such the following: (59) a. someone who I can talk [vp to $<$ who $>$ [v $<$ talk $>$ ] about my problems]

b. *someone who it seems [vp to $<$ who $>[\mathrm{v}<$ seem $>$ ] that the glass is half empty] In both structures in (59), the preposition to has been stranded in spec-VP: however, in (59a), to is stranded in front of a PP argument and the resulting structure is grammatical; by contrast in (59b) to is stranded in front of a that-clause argument and the outcome is ungrammatical. In the light of this constraint, it is plausible to suppose that ghosting of the preposition about in structures like (58) serves to repair a potential violation of PPC.

Furthermore, the extended Ghosting operation which takes place in structures involving Predicate Ghosting can also serve to repair PPC violations - as we can illustrate in relation to our earlier structure (52), repeated below:

(52) You look at some of the other papers, who $<$ I would say about $>$ it's not going to be just the 'News of The World' running dodgy practices

The preposition about is in stranded in spec-VP, so that overtly spelling it out would lead to violation of the Preclausal Preposition Constraint. Ghosting in (52) deletes (inter alia) the illicitly stranded preposition, and so 'repairs' the relevant structure.

Ghosting can also be used to repair potential violations of other constraints, as the following examples illustrate:

(60) a. It's something that we have been training $<$ for $>$ for a long time (Tom Daley, BBC Radio 5)

b. That's what we paid the money $<$ for $>$ for you (Alan Shearer, BBC1 TV)

c. The standard fix is to replace just the offending bushes - something $a$ main dealer will charge around $£ 600<$ for $>$ for parts and labour (Edd China, Discovery TV)

d. Jenny Meadows wants to get back to her main event, which she can certainly do some damage $<$ in $>$ in the European championships later this year (Steve Cram, BBC1 TV)

If the angle-bracketed preposition were stranded by WH-MOVEMENT and pronounced in the position which it occupies in (60), the resulting structure would violate an Iteration Constraint which bars successive occurrences of the same item (Radford 1979, Bošković 2002, Demonte \& Fernández-Soriano 2009) - e.g. two successive occurrences of the preposition for or of the preposition in ${ }^{14}$. However, Ghosting provides a way of rescuing such structures, as we can illustrate in relation to (60a). Let us suppose that the relative clause in (60a) contains the relative wh-pronoun which used as the object of the preposition for. Let us further suppose that which undergoes Prepositional Inversion and thereby moves to spec-PP, forming [pP which [p for] < which $>$ ]. If the resulting PP then moves to spec-CP, this will derive the following structure:

(61) [CP [PP which [P for] < which $>$ ] [C that] we have been training $<\mathrm{PP}>$ for a long time] The resulting $\mathrm{CP}$ violates the Edge Constraint in that it has both an overt $\mathrm{C}$ head (that) and an overt PP specifier (which for < which>). Ghosting of the PP specifier results in: 


$$
\text { [CP }\left[\mathrm{pP}<\text { which }>\left[{ }_{\mathrm{P}}<\text { for }>\text { ] }<\text { which }>\text { ] [C that] we have been training }<\mathrm{PP}>\right.\text { for a long }\right.
$$

Since the resulting structure (62) no longer contains two occurrences of for, there is no violation of the Iteration Constraint barring a succession of two identical items, and so Ghosting provides a way of obviating the constraint.

Nonetheless, the claim that Ghosting can repair constraint violations would appear to be potentially undermined by apparent Island Constraint violations in Ghosting structures such as the following:

(63) a. We want reaction from the Southampton dressing-room, which [the door $<\mathrm{of}>$ ] remains firmly shut (Keith Hill, BBC Radio 5)

b. We've had to buy players from clubs that [the players $<\mathrm{of}>$ ] are not first team players (Jim McClean, Sky Sports TV)

c. We've got a game on that no-one really knows [what's happening <in>] (Presenter, Talk Sport Radio)

d. This is a race you never know [what's going to happen <in>] (Anthony Davidson, BBC Radio 5)

e. We have languages which we don't know [what is going on <in>] (Ken Wexler, talk given to Fifth Annual Conference on Formal Linguistics, Guangdong University of Foreign Studies, China)

If such sentences involve an inverted (overt or null) prepositional wh-object moving to the front of the italicized clause (pied-piping along with it an angle-bracketed preposition which is subsequently ghosted), this will induce violation of the Subject Condition of Chomsky $(1973)$ in $(63 a, b)$ or of the Wh-Island Condition of Ross $(1967,1986)$ in $(63 c-e)$ : this is because the fronted wh-constituent is extracted out of a bracketed Subject Island in (63a,b) and out of a bracketed Wh-Island in (63c-e).

However, there are a number of ways of circumventing this problem. One is to suppose that in a sentence like (63e), which moves on its own from its initial position as the complement of in, transits through spec-PP and then moves to spec-CP in the main clause, so deriving the following structure:

(64) [CP which we don't know [CP what is going on [pp < which $>$ [P in] < which>]]] Since the Wh-Island Constraint bars a copy of a moved constituent inside a wh-island from having an antecedent outside the island, the structure in (64) violates the constraint in that the bold-printed occurrence of which in spec-PP is inside a wh-island clause beginning with what but its italicised antecedent lies outside the island. However, given the reasonable assumption that island constraints hold at a point in the derivation after Ghosting has applied and that ghosted constituents are invisible to island constraints, the structure in (64) can be rescued if the whole PP [pP $<$ which $>$ [p in] $<$ which $>$ ] is ghosted, Note, however, that this involves positing a further kind of PP Ghosting which (while conceptually coherent in itself) differs from the Prepositional Ghosting operation posited earlier (since the latter was specifically linked to Prepositional Inversion and the Edge Constraint). We will therefore explore alternatives which do not involve positing an additional type of Ghosting.

One such is proposed by Paul Postal (pc). He suggests that (under the analysis in Postal 1998) we can deal with sentences like those in (63) by positing that they contain a null resumptive pronoun whose presence ensures that there is no islandhood violation. He 
claims that his analysis can provide a straightforward account of the grammaticality of structures such as the following (Postal, pc: $\varnothing$ denotes a null resumptive pronoun):

(65) There are languages which I would say Bloomfield was probably sure he didn't know [what was going on in $\varnothing$ ], although he never told anyone that

However, while an analysis along the lines of (65) provides a way of obviating violation of the Wh-Island Constraint, it raises questions about the nature (and constraints governing the distribution) of null resumptives, about how the preposition comes to be ghosted in structures like (63), and also about the role played by which in the relative clause that it introduces.

An interesting alternative analysis which does away with the need for null resumptives and provides a principled answer to the question of the role played by which in such structures is provided by Jason Merchant (pc). He suggests that in wh-island cases like (63c-e), Ghosting targets a PP in the matrix clause, so that (63e) has an interpretation loosely paraphraseable as ‘We have languages about which we don’t know what's going on' (related structures being found in Algonquian, Merchant tells us). Under our Ghosting analysis, this would mean that the italicised relative clause in (63e) has the structure bracketed below:

$$
\begin{array}{r}
\text { We have languages [СР [PP which }\left[{ }_{\mathrm{P}}<\text { about }>\right]<\text { which }>\text { ] [С ø] we don't know }<\mathrm{PP}> \\
\text { what is going on] }
\end{array}
$$

The PP headed by about originates as a complement of the matrix verb know: the whpronoun which then moves to spec-PP, and then the whole PP moves to spec-CP, with about being ghosted in order to avoid violating the Edge Constraint (31). Note that if which were to move on its own to spec-CP, this would leave the preposition about stranded in a preclausal position as in (67) below, in violation of the Preclausal Preposition Constraint (PPC) which bars a (bold-printed) preposition from being stranded in front of an (italicised) clause:

(67) *We have languages which we don't know about what is going on

Thus, under our implementation of Merchant's analysis, Ghosting could be said to repair a potential violation of the Preclausal Preposition Constraint.

A significant potential drawback to Merchant's analysis is that it seemingly cannot be extended to handle structures like (63a,b), in which there is no matrix predicate which the PP headed by the ghosted preposition could serve as an argument of. However, we can overcome this problem if we adopt the Predicate Ghosting analysis outlined in §5, and suppose that such sentences involve relativisation of the object of a ghosted preposition which is in turn the argument of a ghosted predicate. On this view, the italicized relative clause in (63a) would have the (simplified) superficial structure bracketed below:

We want reaction from the Southampton dressing-room,

[CP [PP which [P $<$ about $>$ ] $<$ which $>$ ] [C ø] $<$ I would say PP $>$ the door remains firmly shut]

The relative pronoun which originates as the object of the preposition about (the PP about which serving as the specifier of VP, and the clause the door remains shut serving as the complement of VP). By virtue of being caseless, which obligatorily undergoes

Prepositional Inversion and moves to spec-PP. The whole prepositional phrase [PP which [P about] < which>] moves to spec-CP, and the preposition about undergoes Ghosting in order 
to avoid violation of the Edge Constraint (31). There is no subextraction out of any island, and hence no violation of any island constraint.

It should also be noted that the Predicate Ghosting analysis could also be extended to handle wh-island cases like (63c-e). On this view, a sentence like (63e) would have the structure shown in simplified form below:

$$
\text { [СР [PP which }[\mathrm{P}<\text { about }>\text { ] }<\text { which }>\text { ] [ ø] }<\text { I would say PP }>\text { we don't know what is }
$$

going on]]]

The relative pronoun which would originate as the object of the preposition about. By virtue of being caseless, which obligatorily undergoes Prepositional Inversion and moves to spec-PP. The whole prepositional phrase [pP which [p about] < which $>$ ] moves to spec-CP, and the preposition about undergoes Ghosting in order to avoid violation of the Edge Constraint (31). There is no subextraction out of any island, and hence no violation of any island constraint.

Although both the PP Ghosting analysis in (64) and the Predicate Ghosting analysis in (69) yield descriptively adequate analyses, the Predicate Ghosting analysis seems preferable for the following reason. At the end of $\S 4$, we suggested that relative pronouns in English can induce Prepositional Inversion and Ghosting because they are light pronouns with minimal intrinsic semantic content (this being recoverable from their antecedent) and minimal grammatical content (e.g. they lack case): by contrast, interrogative pronouns in English have intrinsic semantic and grammatical content (e.g. they function as interrogative operators which carry gender and D-linking properties, and have no antecedent to identify their properties). If relative (but not interrogative) pronouns in English are light proforms and only light proforms can undergo Prepositional Inversion, then any analysis of Ghosting (like that in 69) which involves Prepositional Inversion predicts that Prepositional Ghosting should only be found in relative clauses, not in interrogative clauses: by contrast, an analysis like (64) which does not involve Prepositional Inversion predicts that Prepositional Ghosting should be found in interrogative clauses as well. In this connection, it is interesting to recall our earlier observation that the BBE corpus contains no clearcut examples of prepositions being ghosted when they have an interrogative object (pace fn.7). This means that all examples of preposition ghosting in wh-clauses would involve relative clauses only.

Irrespective of whether a Ghosting analysis along the lines of (69) is deemed preferable to one along the lines of (64), the key point to emerge from this section is that there is evidence that Ghosting (like deletion operations such as Sluicing) can serve to repair constraint violations.

\section{Response to ghost-busters}

Although we have argued that our Ghosting analysis of gapless relatives proves superior to the alternative analyses we looked at, in this section we discuss potential conceptual, empirical, and theoretical drawbacks to our account raised by would-be ghost-busters (i.e. critics), and consider whether these undermine the Ghosting analysis. We shall argue that this is not the case.

Paul Postal (pc) points out that most of the structures we cite in our paper are ungrammatical (and in some cases unparsable) for him. This may in part be because Preposition Ghosting belongs to a highly colloquial register which more conservative 
speakers find alien to them, and in part because ghosting of prepositions can cause parsing problems in recovering the ghosted preposition. Jason Merchant (pc) makes the related suggestion that the ghosting of prepositions may be the result of a production error. Anonymous et al. (in press) sketch a possible processing analysis in terms of spellout errors induced by memory decay: in simple terms, this amount to claiming that speakers may mistakenly assume that they pied-piped a preposition and so fail to spell out a copy of a preposition at the foot of a wh-chain.

However, what the processing analysis fails to account for is why (in our recordings) there are 243 examples of preposition ghosting in relative clauses, but no clearcut examples of interrogative structures like the following (even though questions occurred frequently in the BBE corpus, e.g. in phone-ins and interviews):

(70) a. *What situation do Obama and the party find themselves <in>?

b. *What do you feel sorry for Everton fans < about>?

c. *Which of these are you familiar $<$ with $>$ ?

d. *Who did that happen $<$ to $>$ ?

e. *What are you working <on> with your suppliers?

This asymmetry follows from the syntactic analysis outlined here, under which relative (but not interrogative) pronouns have caseless light counterparts which can undergo preposition inversion, leading to pied-piping and ghosting.

Bob Borsley (pc) questions the robustness of the Edge Constraint, pointing out that (under a traditional CP analysis) it is seemingly violated by the italicised strings in SubjectAuxiliary Inversion/SAI structures such as:

(71) a. [сР How [C could] he have known]?

b. [СР Never [c had] he heard anything so silly]

c. [ ${ }_{\mathrm{CP}}$ Such [c is] life]

Under a traditional CP analysis, the inverted auxiliary would be in C, and the fronted constituent preceding it would be in spec-CP, so resulting in a structure in which a CP phase has an overt head and an overt specifier. However, an alternative possibility is that the inverted string is not contained within a CP phase but rather within a projection positioned below the CP phase - as is suggested by the fact that the italicized inverted string is positioned below the phase head that in CPs like those bracketed below:

(72) a. The strange thing with Joe Cole going to Lille is [that why did nobody in the Premier League want him?] (Ian McGarry, BBC Radio 5)

b. He said [that never had he heard anything so silly]

c. He mused [that such is life]

If so, the inverted strings italicised in (71) would not be immediately contained in a phasal projection, and would not present any empirical challenge to the Edge Constraint.

Furthermore, there is syntactic evidence to suggest that the inverted auxiliary is contained within a lower peripheral projection than the constituent preceding it in sentences like (71). This can be illustrated for wh-questions by sentences such as those below (73a being from Hudson 2003, and 73b-c from Haegeman 2012):

(73) a. Why, in Scotland, do they eat haggis? (Hudson 2003) 
b. So how, from this, does the team conclude that risks to mothers who have Caesareans are actually 2.7 times greater? (Independent, 30.01.2010, p. 26 col 2)

c. In what circumstances, during the exam, do you allow students to use notes? In (73a-c), the bold-printed wh-phrase is separated from the underlined inverted auxiliary by an intervening (italicised) PP which Haegeman (2012) takes to be the specifier of a separate Topic Phrase projection. Indeed, several different peripheral projections can intervene between a fronted wh-constituent and an inverted auxiliary, as below:

(74) Where, Steve, in your view, in his team selection, did Capello get things wrong ? This suggests that the auxiliary in such structures is contained in a much lower projection than the wh-phrase (e.g. in terms of the template in Rizzi 1997, it is the head of FinP).

Borsley (pc) further suggests that that wh+that strings such as those italicised below also violate the Edge Constraint:

(75) a. [CP What a mine of useless information [C that] I am!] (Terry Wogan, BBC Radio 2; Radford 1988:501)

b. People can see [cP how successful [C that] they’ve been] (Anonymous extortionist, BBC World Service)

c. It's quite clear [CP on which side of the Blair-Brown divide [C that] Alistair Campbell comes down on (Political correspondent, BBC Radio 5)

d. I'm aware of the speed [ср with which [C that] they work] (Tim Vickery, BBC Radio 5)

e. People aren't told [CP how [C that] every single family in Britain is safer (Liberal Democrat spokesman, BBC Radio 5)

This type of structure is frequently encountered in spoken English, and the BBE corpus contains 76 examples of them. However, it should be noted that other constituents can intervene between the wh-constituent and that, like those underlined below:

(76) a. I wonder why, like women's football, that we haven't seen it so often (Listener, BBC Radio 5)

b. I asked her how, as a 20-year old girl really, that she'd managed to cope with his death (News reporter, BBC Radio 5)

c. Sometimes we lose sight of how, in the very recent past, that this has come about (John Cross, Talk Sport Radio)

d. Capello has to know who, when the chips are down, that he can trust to do a job for the team (Graham Taylor, BBC Radio 5)

This suggests that the wh-constituent and that are contained within separate projections in such structures, e.g. with wh being the only overt constituent on the edge of ForceP and that being the only overt constituent on the edge of FinP. Furthermore, Zwicky (2002) has argued that exclamatives like (75a) are reduced cleft sentences, so that (75a) has a structure paraphraseable as 'What a mine of useless information it is that I am!' If so, the wh-phrase and the complementiser are contained in separate projections, and such sentences do not violate the Edge Constraint ${ }^{15}$.

A further type of structure which poses a potential threat to the Edge Constraint is that bracketed below (where $e$ denotes an empty TP):

(77) He bought a present, but I have no idea [CP [pp who [p for] < who>] [с ø] e]] The bracketed clause in (77) represents a type of Ellipsis termed Swiping by Merchant (2001, 2002, 2008): if the non-ellipsed string who for is a PP which has undergone 
Prepositional Inversion (with who moving from complement to specifier position within PP), the relevant PP will violate the Edge Constraint. However, a number of recent analyses have argued that who (in such structures) occupies a position outside the PP containing for. For example, Culicover and Jackendoff (2005:272) maintain that who is positioned on the edge of the clause, and that for is stranded internally within an in situ PP. Working within a very different framework, Richards (1997, 2001), van Craenenbroeck (2004, 2010), Hartman and Ai (2009) and Radford and Iwasaki (2012) argue that who is positioned on the edge of a CP/ForceP projection, and for on the edge of a lower FocP projection. Under either type of analysis, structures like (77) do not violate the Edge Constraint.

The final problem which we will consider here arises in relation to a possibility which we earlier skipped over in relation to how Ghosting can apply to a structure such as the following:

$$
\begin{aligned}
& {\left[{ }_{\mathrm{CP}}[\mathrm{PP} \text { which }[\mathrm{P} \text { in] }<\text { which }>\text { ] [C that] the Scotland players will raise their }\right.} \\
& \text { game }<\mathrm{PP}>\text { ] }
\end{aligned}
$$

We considered three well-formed outcomes which Ghosting can give rise to in (43), but overlooked a fourth alternative. Suppose that the complementiser that is ghosted (in order to ensure that CP doesn't violate the Edge Constraint 31), and that the wh-pronoun which is also ghosted, in order to ensure that the fronted PP does not violate the constraint either. The structure resulting from this double application of Ghosting will be:

$$
\begin{gathered}
{\left[{ }_{\mathrm{CP}}\left[\mathrm{pP}_{\mathrm{P}}<\text { which }>[\mathrm{P} \text { in }]<\text { which }>\right][\mathrm{C}<\text { that }>\text { ] the Scotland players will raise their }\right.} \\
\text { game }<\mathrm{PP}>\text { ] }
\end{gathered}
$$

However, the resulting structure (which contains a preposition stranded in spec-PP at the beginning of a clause) is ungrammatical (cf. *'This is a match in the Scotland players will raise their game'). This would seem to mean that the Ghosting analysis wrongly predicts that we should find gapless relatives like (78) with a preposition stranded at the beginning of a relative clause. Since structures like (78) are unattested in spoken or written English, they provide a strong counterexample to the Ghosting analysis, do they not?

The answer is 'Not if the ungrammaticality of structures like (78) can be attributed to violation of an independent constraint.' One possibility along these lines is that (78) is ruled out by the same constraint that rules out what Postal (1972) called preposition dangling in structures like $(79 b, c)$ below:

(79) a. Max is the only person [ср who I believe [ср Mary thinks [CP John talked to]]]

b. *Max is the only person [CP who I believe [CP Mary thinks [CP to John talked]]]

c. *Max is the only person [CP who I believe [CP to Mary thinks [CP John talked]]] In all three sentences in (79), the italicised relative pronoun who originates as the object of the bold-printed preposition to. In (79a), who undergoes wh-movement on its own, leaving the preposition to stranded in situ. In (79b), the preposition to is pied-piped along with who to the edge of the most deeply embedded CP, but then is left stranded in spec-CP in the innermost clause when who subsequently moves on its own to the edge of the other two bracketed CPs. In (79c), to is pied-piped along with who to the edge of the inner and intermediate CPs, but then is left stranded on the edge of the intermediate CP when who subsequently moves on its own to the edge of the outer $\mathrm{CP}$. This raises the question of whether structures like (78) are ruled out by the same constraint which bars structures like (79b, c). But what kind of constraint might be involved?

One possible candidate is the following: 


\section{Preposition Dangling Constraint/PDC}

No preposition can be left dangling inside a PP on the edge of a phase

PDC would rule out structures like (79b,c), since in both cases a preposition is left dangling inside a PP on the edge of a CP phase. On the other hand, it would (quite correctly) not rule out structures such as (59a) in which a preposition is left stranded on the edge of a nonphasal VP, nor would it rule out structures such as the following (from Chaves, forthcoming, brought to our attention by Bob Borsley) in which a preposition is stranded inside an in situ PP adjunct:

(81)(a) What did he fall asleep complaining about?

(b) Who would you rather sing with?

More importantly for present purposes, however, PDC would rule out structures like (78), and so overcome what would otherwise have been a problematic example for our analysis.

\section{Summary}

This paper began by looking at gapless appositive relatives like And she decided to move out, which I think she's crazy, and considering the claim made by Loock (2007) and others that which in this kind of structure cannot be a relative pronoun because it has no antecedent, and instead should be analysed as a subordinating conjunction which connects a subordinate clause to a main clause. In $\S 2$, we argued against the subordinating conjunction analysis by showing that which behaves differently from typical subordinating conjunctions like although in that (e.g.) the clause it introduces cannot precede the main clause. We further argued that which can have an inanimate nominal antecedent in gapless appositives, and that who is used in place of which in gapless appositives with a human antecedent: we concluded from this that the wh-word in gapless appositives is indeed a relative pronoun. We went on to show that free and restrictive relative clauses can also be gapless. In $\S 3$, we considered whether Caponigro and Pearl's analysis of silent prepositions in free relatives, interrogatives and adverbial nominals could be extended to handle gapless relatives in spoken English, but argued against this on the grounds (inter alia) that any such analysis would wrongly predict that gapless relative clauses cannot relativise the object of an unstrandable preposition. In $\S 4$, we proposed an alternative analysis of gapless relatives under which the wh-pronoun functions as the object of a preposition which is given a null spellout as a result of the Ghosting of the preposition or of the PP it heads. We argued that gapless relatives have arisen because colloquial English has developed caseless lightpronoun counterparts of relative which/who, and that these obligatorily move to their criterial position in spec-PP (outside the case domain of the preposition) by Prepositional Inversion and are thereafter frozen in place. Consequently, the inverted wh-pronoun obligatorily pied-pipes the preposition along with it under wh-movement, and the preposition must be ghosted in order to avoid violation of the Edge Constraint. In §5, we looked at gapless relatives which have a topic-comment interpretation, and proposed that they involve a ghosted topical preposition like about which in turn serves as the argument of a ghosted verb of SAYING (akin to the ghost verb assumed by Ross 1970 in declarative root clauses); we argued that in such extended cases of Ghosting, all the constituents intervening between relativizer and gap are ghosted. In §6, we went on to argue Ghosting 
(like other deletion operations such as VP Ellipsis and Sluicing) can serve to repair structures which would otherwise induce constraint violations. In §7, we considered (but argued against) a range of potential objections to the Ghosting analysis.

Our research has led to important descriptive and theoretical conclusions. The main descriptive conclusion to be drawn from it is that gapless relatives are not in fact gapless, but rather the relative pronoun in such structures serves as the complement of a ghosted preposition.

At a theoretical level, we have provided a new source of evidence for a deletion operation called Ghosting which is defined as deletion not requiring the presence of an antecedent. In Collins and Postal (2012), all the evidence for ghosting was given in terms of syntactic conditions on pronominal agreement. In this paper, we provide independent evidence for ghosting in terms of gapless relatives in spoken English.

To the extent that Ghosting (i.e. deletion in the absence of an antecedent) is possible, many issues in the syntax-semantics interface (such as interpreting "begin the book" as "begin reading the book") will have to be rethought. In considering cases where some constituent is understood to be present semantically, we cannot automatically infer from the mere absence of an antecedent that deletion has not taken place.

\section{References}

AOUN, J. \& LI, Y.A. 2003. Essays on the Representational and Derivational Nature of Grammar. Cambridge, MA: MIT Press.

BENINCÀ, P. 2001 The position of Topic and Focus in the left periphery. Current Studies in Italian Syntax: Essays Offered to Lorenzo Renzi, ed. G. Cinque \& G. Salvi, 39 - 64. Amsterdam: Elsevier-North Holland. BENINCÀ, P. 2001. A detailed map of the Left Periphery of Medieval Romance. Crosslinguistic Research in Syntax and Semantics, ed. R. Zanuttini et al., 53 - 86. Washington: Georgetown University Press. BENINCÀ, P. 2010a. Lexical complementisers and headless relatives. Draft paper, University of Padova. (To appear in Functional Heads, ed. L. Brugè et al. Oxford: Oxford University Press).

BENINCÀ, P. 2010b. La periferia sinistra. Grammatica dell'italiano antico, ed. G. Salvi \& L. Renzi, 27 - 59. Bologna: Il Mulino.

BENINCÀ, P. \& POLETTO, C. 2004. Topic, focus and V2: Defining the CP sublayers. The structure of CP and IP, ed. L. Rizzi, 52-75. Oxford: Oxford University Press. BIANCHI, V. 1995. Consequences of Antisymmetry for the Syntax of Headed Relative Clauses. PhD dissertation, Scuola Normale Superiore, Pisa. BIANCHI, V. 1999 Consequences of Anti-symmetry: Headed Relative Clauses. Berlin: Mouton de Guyter.

BIANCHI, V. 2000. The raising analysis of relative clauses: A reply to Borsley. Linguistic Inquiry 31, 123 - 40.

BOCCI, G. 2004. Contrastive Focalisation on Topics and Preverbal Subjects in Italian. Rivista di Grammatica Generativa 29, 3 - 60.

BOECKX, C. \& LASNIK, H. 2006. Intervention and Repair. Linguistic Inquiry 37, 150 155. 
BORSLEY, R. 1997. Relative clauses and the theory of phrase structure. Linguistic Inquiry, 28, $629-647$.

BORSLEY, R. 2001. More on the raising analysis of relative clauses. Unpublished paper, University of Essex, http://privatewww.essex.ac.uk/ rborsley/relatives.pdf.

BOŠKOVIĆ, ž. 2002. On multiple wh-fronting. Linguistic Inquiry 33, 351 - 383.

BOŠKOVIĆ, Ž. 2011. Rescue by PF Deletion, Traces as (Non)interveners, and the That-

Trace Effect. Linguistic Inquiry 42, 1 - 44.

BOŠKOVIĆ, ž. \& LASNIK, H. 2003. On the distribution of null complementisers. Linguistic

Inquiry 34, 527 - 46.

BRITAIN, D. 2008. Grammatical variation in England. Language in the British Isles, ed. D. Britain, 75 - 104. Cambridge: Cambridge University Press.

CAPONIGRO, I. \& PEARL, L. 2008. Silent prepositions: Evidence from free relatives. The Syntax and Semantics of Spatial P, ed. A. Asbury, J. Dotlačil, B. Gehrke \& R. Nouwen, 365 - 385. Amsterdam: Benjamins.

CAPONIGRO, I. \& PEARL, L. 2010. The nominal nature of where, when and how: Evidence from free relatives. Linguistic Inquiry 40, 155 - 164.

CARDinaletTI, A. 2004. Towards a Cartography of Syntactic Positions. The Structure of CP and IP: The Cartography of Syntactic Structures, vol.2, ed. L.Rizzi, 115 - 165. Oxford: Oxford University Press.

CHAVES, R. P. (in press). On the grammar of extraction and coordination. To appear in Natural Language and Linguistic Theory.

CHESHIRE, J., ADGER, D. \& FOX, S. 2010. Relative who and the actuation problem. Ms. Queen Mary University of London.

CHOMSKY, N. 1972. Some empirical issues in the theory of transformational grammar.

Goals of Linguistic Theory, ed. P.S. Peters, 63 - 130. Englewood Cliffs: Prentice Hall Inc.

CHOMSKY, N. 1973. Conditions on transformations. A Festschrift for Morris Halle, ed. S.R. Anderson \& P.Kiparsky, 232 - 286. New York: Holt, Rinehart and Winston.

CHOMSKY, N. 1977. On wh-movement. Formal Syntax, ed. P.W. Culicover, T. Wasow \& A. Akmajian, 71 - 132. New York: Academic Press.

CHOMSKY, N. 1986. Barriers. Cambridge, MA: MIT Press.

CHOMSKY, N. 1995. The Minimalist Program. Cambridge, MA: MIT Press.

CHOMSKY, N. \& LASNIK, H. 1977. Filters and Control. Linguistic Inquiry 8, 425 - 504.

CINQUE, G. 1990. Types of $\bar{A}$-Dependencies. Cambridge, MA: MIT Press.

CINQUE, G. \& RIZZI. L. 2010. The cartography of syntactic structures. The Oxford Handbook

of Grammatical Analysis, ed. B. Heine \& H. Narrog, 51 - 65. Oxford: Oxford University

Press.

COLLINS, C. 2007. Home sweet home. NYU Working Papers in Linguistics 1, 1 - 34.

COLLins, C. \& POSTAL, P.M. (2012) Imposters: A Study of Pronominal Agreement.

Cambridge, MA: MIT Press.

CRAENENBROECK, J. VAN. 2004 Ellipsis in Dutch Dialects. PhD diss., Leiden University.

CRAENENBROECK, J. VAN. 2010. The syntax of Ellipsis: Evidence from Dutch Dialects.

Oxford: Oxford University Press.

CRUSCHINA, S. 2006. Informational focus in Sicilian and the left periphery. Phases of

Interpretation, ed. M. Frascarelli, 363 - 385. Berlin: Mouton de Gruyter. 
Culicover, P.W. \& JACKEndofF, R. 1999. The view from the periphery: The English comparative correlative. Linguistic Inquiry 30, 543 - 571.

DEMONTE, V. \& FERNÁNDEZ SORIANO, O. 2009. Force and finiteness in the Spanish complementizer system. Probus 21, 23 - 49.

EMONDS, J.E. 1976. A transformational approach to English syntax. New York: Academic Press.

EMONDS, J.E. 1987. The Invisible Category Principle. Linguistic Inquiry 18, 613 - 632. EPSTEIN, S.D., PIRES A., \& SEELY, T.D. 2005. EPP in T: More controversial subjects. Syntax 8, $65-80$.

FOX, D. \& LASNIK, H. 2003. Successive-Cyclic Movement and Island Repair: The Difference between Sluicing and VP-Ellipsis. Linguistic Inquiry 34, 143 - 154.

FRASCARELLI, M. \& HINTERHÖLZL, R. 2007. Types of topics in German and Italian. On Information Structure, Meaning and Form, ed. S. Winkler \& K. Schwabe, 87 - 116. Amsterdam: John Benjamins.

GELDEREN, E. VAN. 2009. Renewal in the left periphery: Economy and the complementiser layer. Transactions of the Philological Society 107, 131 - 195.

HAEGEMAN, L. 1994. Introduction to Government and Binding Theory: Second Edition. Oxford: Blackwell.

HAEGEMAN, L. 2000 Inversion, non-adjacent inversion and adjuncts in CP. Transactions of the Philological Society 98, 121 - 160.

HAEGEMAN, L. 2003. Notes on long adverbial fronting in English and the left periphery. Linguistic Inquiry 31, 640 - 649.

HAEGEMAN, L. 2006a. Argument Fronting in English, Romance CLLD and the Left Periphery. Negation, Tense and Clausal Architecture: Cross-linguistic Investigations, ed. R. Zanuttini, H. Campos, E. Herburger, \& P. Portner, 27 - 52. Georgetown: Georgetown University Press.

HAEGEMAN, L. 2006b. Conditionals, factives and the left periphery. Lingua 116, 1651 1669.

HAEGEMAN, L. 2007. Operator movement and topicalization in adverbial clauses. Folia Linguistica 18, 485 - 502.

HAEGEMAN, L. 2009. The movement analysis of temporal adverbial clauses. English Language and Linguistics 13, 385-408.

HAEGEMAN, L. (2010) The internal syntax of adverbial clauses. Lingua 120: 628-648. HAEGEMAN, L. 2011. The movement derivation of conditional clauses. Linguistic Inquiry 41, 595 - 621.

HAEgeman, L. (in press). Main Clause Phenomena and the Clause Periphery. Oxford: Oxford University Press.

HARTMAN, J. \& AI, R.R. 2009. A Focus account of Swiping', Ms. MIT and Harvard. HAWKINS, J.A. 2001. Why are categories adjacent? Journal of Linguistics 37, 1 - 34. HORNSTEIN, N., LASNIK, H. \& URIAGEREKA, J. 2003. The dynamics of islands: Speculations on the locality of movement. Linguistic Analysis 33, 149 - 175.

Hudson, Richard. 2003. Trouble on the left periphery. Lingua 113: 607 - 642.

KATZ, J.J. \& POSTAL, P.M. (1964) An Integrated Theory of Linguistic Descriptions. Cambridge, MA: MIT Press.

KAYNE, R.S. 1994. The Antisymmetry of Syntax. Cambridge, MA: MIT Press. 
KAYNE, R.S. 2005. Movement and Silence. Oxford: Oxford University Press. KJELLMER, G. 1988. Conjunctional/adverbial which in substandard English. Studia Anglica Posnaniensa 21, 125 - 37.

KJELLMER, G. 2010. And which: A note on (more or less) coordinated relatives. English Studies 91, 457 - 466.

KOOPMAN, H. 2000. The Syntax of Specifiers and Heads. New York: Routledge. KOOPMAN, H. \& SZABOLSCSI, A. 2000. Verbal complexes. Cambridge, MA: MIT Press. KUHA, M. 1994. Attitudes towards users of co-ordinate which. Unpublished paper, Indiana University, Bloomington.

LASNIK, H. 2001. When Can You Save a Structure by Destroying It? Proceedings of the North East Linguistic Society 31, 301 - 320.

LOOCK, R. 2005 Appositive Relative Clauses in Contemporary Written and Spoken English: Discourse Functions and Competitive Structures, $\mathrm{PhD}$ diss., University of Lille III (UMR 8528 SILEX, CNRS).

LOOCK, R. 2007. Are you a good which or a bad which? The relative pronoun as a plain connective. Connectives as Discourse Landmarks, ed. A. Celle \& R. Huart, 71-87. Amsterdam: Benjamins. LOOCK, R. 2010. Appositive Relative Clauses in English: Discourse Functions and Competing Structures. Amsterdam: John Benjamins.

MCCAWLEY, J. 1988. Adverbial NPs: Bare or clad in see-through garb? Language 64, 583 590.

MERCHANT, J. 2001. The Syntax of Silence: Sluicing, Islands, and the Theory of Ellipsis. Oxford: Oxford University Press.

MERChANT, J. 2002. Swiping in Germanic. Studies in Comparative Germanic Syntax, ed. W. Abraham and J.-W. Zwart, 295-321. Amsterdam: John Benjamins.

MERCHANT, J. 2008. Variable island repair under ellipsis. Topics in Ellipsis, ed. K. Johnson, 132-153. Cambridge: Cambridge University Press.

MILLER, J. 1988. That: A relative pronoun? Edinburgh Studies in the English Language, ed. J.M. Anderson \& M. Macleod, 113 - 119. Edinburgh: John Donald.

MILLER, J. 1993. The grammar of Scottish English. Real English, ed. J. Milroy \& L. Milroy, 99-138. London: Longman.

NAKAO, C. 2009. Island Repair and Non-Repair by PF Strategies. PhD diss., University of Maryland.

NOMURA, T. 2006. ModalP and Subjunctive Present. Tokyo: Hituzi Syobo.

ORMAZABAL, J. (1995) The Syntax of Complementation. PhD diss., University of

Connecticut.

POLETTO, C. 2000. The Higher Functional Field. Evidence from Northern Italian Dialects. Oxford: Oxford University Press.

POLLARD, C. \& SAG, I. (1994) Head-Drive Phrase Structure Grammar. Chicago: University of Chicago Press.

POSTAL, P.M. 1972. On Some Rules that Are Not Successive Cyclic. Linguistic Inquiry 3, $211-222$.

POSTAL, P. 1998. Three studies of extraction. Cambridge, MA: MIT Press.

RADFORD, A. 1979. The functional basis of transformations. Transactions of the 
Philological Society, 77, 1 - 42

RADFORD, A. 1997. Syntactic Theory and the Structure of English. Cambridge: Cambridge University Press.

RADFORD, A. \& IWASAKI, K. 2012. Swiping in English: Construction or Derivation? Ms., University of Essex and Waseda University.

RADFORD, A., FELSER, C. AND BOXELL, O. in press. Preposition copying and pruning in present-day English. To appear in English Language and Linguistics.

RICHARDS, N. 1997. What moves where when in which language? PhD diss., MIT.

RICHARDS, N. 2001. Movement in Language: Interactions and Architectures. Oxford:

Oxford University Press.

RIEMSDIJK, H. VAN. 1978. A Case Study in Syntactic Markedness: The Binding Nature of Prepositional Phrases. Dordrecht: Foris Publications.

RIZZI, L. 1990. Relativised Minimality. Cambridge, MA: MIT Press.

RIZZI, L. 1996. Residual verb second and the wh-criterion'. Parameters and Functional

Heads, ed. A. Belletti \& L. Rizzi, 63 - 90. Oxford: Oxford University Press.

RIZZI, L. 1997. The fine structure of the left periphery. Elements of Grammar, ed. L.

Haegeman, 281 - 337. Dordrecht: Kluwer.

RIZZI, L. 2001. On the position "Int(errogative)" in the left periphery of the clause. Current

Issues in Italian Syntax, ed. G. Cinque \& G. Salvi, 287-296. Amsterdam: Elsevier.

RIZZI, L. 2004. Locality and Left Periphery. Structures and Beyond: The Cartography of Syntactic Structures, vol.3, ed. A. Belletti, 223 - 251. Oxford: Oxford University Press. RIZZI, L. 2006. On the form of chains: Criterial positions and ECP effects. Wh-Movement: Moving On, ed. L. Cheng \& N. Corver, 97 - 133. Cambridge, MA: MIT Press.

RIZZI, L. \& SHLONSKY, U. 2005. Strategies of subject extraction. Ms., Universities of Siena and Geneva.

ROBERTS, I. 2004. The C-system in Brythionic Celtic languages and the EPP. The Structure of CP and IP. The Cartography of Syntactic Structures, vol. 2, ed. L. Rizzi, 297 - 328. Oxford: Oxford University Press.

ROBERTS, I. \& ROUSSOU, A. 2002. The extended projection principle as a condition on the tense dependency. Subjects, Expletives and the EPP, ed. P. Svenonius, 125-155. Oxford: Oxford University Press.

ROSS, J.R. 1967. Constraints on Variables in Syntax. PhD diss., MIT.

ROSS, J.R. 1969. Guess Who? Chicago Linguistic Society Papers 5, 252 - 286.

ROSS, J.R. 1970. On declarative sentences. Readings in English Transformational Grammar, ed. R. Jacobs \& P.S. Rosenbaum, 222-272. Waltham, MA: Ginn.

ROSS, J.R. 1986 Infinite Syntax. Norwood, NJ: Ablex Publishing Corporation. SAFIR, K. 1986. Syntactic Chains. Cambridge: Cambridge University Press.

SCHÜTZE, C. 2001. On the nature of default case. Syntax 4, 205 - 38.

TAGLIAMONTE, S. 2002. Variation and change in the British relative marker system.

Relativisation on the North Sea Littoral, ed. P. Poussa 117-134. Munich: Lincom Europa. TERZI, A. 2008. Locative prepositions as modifiers of an unpronounced noun. Proceedings of WCCFL 26, 471 - 480.

TERZI, A. 2010a. On null spatial Ps and their arguments. Catalan Journal of Linguistics 9, $167-187$. 
TERZI, A. 2010b. Locative Prepositions and Place. Mapping Spatial PPs. The Cartography of Syntactic Structures, volume 6, ed. G. Cinque \& L. Rizzi, 196 - 224. Oxford: Oxford University Press.

TOTTIE, G. 1997. Relatively speaking: Relative marker usage in the British National Corpus. To Explain the Present: Studies in the Changing English Language in Honour of Matti Rissanen, ed. T. Nevalainen \& L. Kahlas-Tarkka, 465 - 481. Helsinki: Société Néophilologique.

TSAI, WEI-TIEN DYLAN. 1997. On the absence of island effects. Tsing Hua Journal of Chinese Studies 27, 125 - 149.

VERGNAUD, J.-R. 1974. French Relative Clauses. PhD diss., MIT.

ZHANG, N. 2008. Gapless relative clauses as clausal licensors of relational nouns. Language and Linguistics 9, 1005 - 1028.

ZWICKY, A.M. 2002. I wonder what kind of construction that this example illustrates. The Construction of Meaning, ed. D. Beaver, L.D. Casillas Martínez, B.Z. Clark \& S.

Kaufmann 219-248. Stanford: CSLI Publications.

Details of co-author 1 removed

Details of co-author 2 removed

\section{Footnotes}

1. Earlier versions of this paper were presented by Anonymous at the Guangdong University of Foreign Studies in December 2011, the Autonomous University of Barcelona in May 2012, and the University of Sevilla in May 2012. We are grateful to the audiences there and to Bob Borsley, Mai Kuha, Kristy Liu, Rudy Loock, Javier Martín-González, Jason Merchant, Paul Postal, Arhonto Terzi and Niina Zhang for helpful observations. Structural representations are simplified in various ways, including by showing only those parts of the structure relevant to the discussion at hand and by not showing intermediate projections in labelled bracketings; <angle brackets> are used to mark silent constituents. Authors' names are listed in alphabetical order; please send correspondence to both authors.

2. Chomsky (1977) takes the null operator in relatives like (1b,c) to be a deleted wh-word, whereas Rizzi (1990), Cinque (1990), Haegeman (1994) and Radford (1997) take it to be an inherently null operator. Different versions of the ANTECEDENT RAISING analysis can be found in Vergnaud (1974), Bianchi (1995, 1999, 2000), Kayne (1994), and Aoun and Li (2003); for a critical perspective, see Pollard and Sag (1994), and Borsley (1997, 2001). For expository purposes, we will assume a WH-MOVEMENT analysis of gap relatives and will set aside the possibility (argued for in Chomsky 1986, 1995) that a fronted wh-constituent moves to the edge of a (transitive) verb phrase before moving to the edge of CP.

3. The data were taken from live unscripted broadcasts in order to avoid possible prescriptive influences from copy editors. The main sources were popular sports broadcasts from BBC Radio 5 Live, BBC Radio 5 Sports Extra, BBC World Service, Talk Sport 
Radio, BBC TV, ITV and Sky Sports TV. Programmes recorded included sports discussion forums (like Radio 5's Monday Night Club and Sky's Sunday Supplement), sports phoneins (like Radio 5's World Football Phone-In and Sky's You're on Sky Sports) and live sports commentaries. The data were digitally recorded (and relevant examples transcribed) by Anonymous from May 2010 to May 2012. The recordings comprised around 700 hours and 5 million words.

4. It should be noted, however, that Kjellmer, Kuha and Loock all claim that which can function as a co-ordinating conjunction in other uses.

5. Relative pronouns with clausal antecedents generally either follow the antecedent, or are embedded internally within it, as in (i) below:

(i) The Prime Minister (which annoyed the opposition) refused to back down However, Rudy Loock (pc) draws our attention to examples such as the following, where which appears to precede the clause which serves as its antecedent (although which must follow the and introducing the relevant clause):

(ii) He quit his job, and (which was really surprising) found another one the next day It is not entirely clear what is going on in such cases, but one possibility (suggested by the fact that the Italian counterpart of which in such sentences is cosa che 'thing which') is that which has a null antecedent in such cases (e.g. perhaps a null counterpart of something).

6. Although (to simplify exposition) we adopt the traditional CP analysis of the clause periphery here, work within the Cartographic tradition over the past two decades has argued that CP should be split into a number of distinct peripheral projections: see, for example, Benincà (2001, 2006, 2010a, 2010b), Benincà \& Poletto (2004), Bocci (2004), Cardinaleti (2004), Cinque and Rizzi (2010), Cruschina (2006), Frascarelli \& Hinterhölzl (2007), Haegeman (2000, 2003, 2006a, 2006b, 2007, 2009, 2010, 2011, in press), Poletto (2000), Rizzi (1997, 2001, 2004, 2006), and Rizzi \& Shlonsky (2005). From a Cartographic perspective, the wh-pronoun in gapless relatives could be taken to be the specifier of the highest projection in the clause periphery (e.g. Spec-ForceP in the analysis of Rizzi 1997).

7. The only potential example in the BBE corpus of a preposition being silent when it has an interrogative complement is the following (representing the annual British obsession with whether Andy Murray can win the Wimbledon tennis tournament):

(i) What sort of shape is he, going into Wimbledon, then? (Mark Pougatch, BBC Radio 5)

Here it might seem as if what sort of shape is the complement of a 'missing' preposition in. If so, this may be an example of a silent preposition (in the sense of Caponigro and Pearl 2008, 2010) rather than a preposition which is ghosted in wh-clauses, since examples like (ii) below suggest that some speakers allow in to be silent in nominals as well:

(ii) He’s been <in> good shape all weekend (Ross Braun, BBC1 TV) Alternatively, (i) could be a (prepositionless) question about his physical shape (e.g. whether he is lean and mean). A third possibility is that (in informal rapid speech) the monosyllabic bisegmental preposition in at the end of a sentence underwent phonological 
reduction/truncation by virtue of being weak and unstressed (the main stress falling on shape).

8. On the internal structure of PP, see Terzi (2008, 2010a, 2010b). Bob Borsley (pc) asks why (in standard varieties of English) only to/at can be ghosted (and not e.g. from in Where is he coming *(from)?). Collins (2007) takes from to have a null at-complement, in which case there is also ghosting of at in such sentences. More generally, it may be that to/at are relatively 'light' prepositions whose locative interpretation can be inferred from their locative complement. In spoken English, it appears (from examples like that below) that a wider range of prepositions can be ghosted with a fronted $r$-pronoun complement:

(i) That's [where people are coming < from > in large numbers] (Interviewee, BBC Radio 5) Borsley also raises the question of how to deal with standard English "examples like the day I left, which appear to involve the deletion of on given the day on which I left, and the reason I left, which presumably involve deletion of for given the reason for which I left." However, such examples are unlikely to be wh-ghosted variants of which relatives, since structures like *the day/reason which I left are ungrammatical: it is more likely that they are wh-ghosted variants of the day when I left and the reason why I left. Hence they can be treated like standard English: Where did he go? When did he leave? Why did he leave? We assume that all of these involve ghosted pied-piped prepositions.

9. A possibility which we leave open here is that deletion of the complementiser that may be the result of a different type of operation from Ghosting. This is suggested by the fact that that can be deleted in cases like I said (that) I was tired, where its deletion does not serve to obviate violation of the Edge Constraint, and may be connected to the fact that it has little semantic content if clauses are interpreted as declarative by default (as in Roberts and Roussou 2002 and Roberts 2004). Some have suggested that that null complementisers arise via cliticisation to a higher head (e.g. Ormazabal 1995, Bošković and Lasnik 2003, and Epstein, Pires and Seely 2005); for discussion of further factors governing the null spellout of that, see Hawkins (2001) and Nomura (2006). A related question is whether deletion of relative pronouns is the result of Ghosting, or of an alternative deletion operation (permissible where the content of the relative pronoun can be recovered from a locally c-commanding antecedent).

10. Bob Borsley (pc) suggests a simpler Ghosting analysis, under which "Certain prepositions can be deleted in certain registers in their original position before the copy of a moved wh-element." However, this analysis would wrongly predict (i) that prepositions are deleted when they have an interrogative wh-complement (and yet we have shown that this only happens when they have a relative pronoun complement), and (ii) that unstrandable prepositions cannot be ghosted (contrary to what we find in 20-24).

11. Rudy Loock (pc) asks about the relative frequency of gapless relatives with which and who. Our recordings contain 118 relative clauses where which is the object of a ghosted preposition, and 17 in which who is the object of a ghosted preposition. Moreover, if we look at ghosted wh-less relative clauses (i.e. that relatives and zero relatives), we find that preposition ghosting occurs in 75 relative clauses with a non-animate antecedent (where, by 
hypothesis, which has been inverted and ghosted), but only in 8 relative clauses with a human antecedent (where, by hypothesis, who has been inverted and ghosted). In our terms, this could mean that for some speakers, only which and not who has developed a caseless counterpart (and so can undergo Prepositional Inversion and trigger Prepositional Ghosting), whereas for other speakers both which and who have caseless counterparts.

12. However, Kristy Liu (pc) points out that many of the types of gapless relative discussed in this paper have no immediate counterparts in Chinese, suggesting that any potential parallel is far from exact.

13. A question raised by the analysis in $(52,54)$ is why the clausal complement of SAY can't be introduced by the overt complementiser that: the answer presumably lies in a constraint that the complement of a ghosted predicate cannot be headed by an overt complementiser (an assumption necessary under Ross's analysis in 53b, in order to account for why declarative main clauses are not introduced by that). A second question is how Predicate Ghosting can seemingly delete a non-constituent string like I WOULD SAY. The answer may be that the wh-clause What else could he have done in the circumstances? is moved to the edge of a peripheral functional projection FP which is above TP but below the $\mathrm{CP}$ containing which, as in (i) below

(i) [ст which [FP what else could he have done... [тр I would say about $<$ which $><$ what

What we have termed Predicate Ghosting would then involve deletion of a unitary else...>]]] constituent (i.e. of the whole of TP). Such an analysis would account for the fact that we often find a pause after which. Fronting of the italicised clause in (i) may be related to fronting of the italicised clause in structures like:

(ii) 'What else could he have done?' you might say/ask/wonder.

14. However, a sequence like for-for in (60a) can be ameliorated if there is a pause between the two words, or if the first for has a full vowel and the second has a reduced vowel. This may be why one of the two authors finds the non-ghosted counterparts of (60) 'awkward' while the other finds them 'unacceptable'.

15. However, if wh+that structures in spoken English don't necessarily violate the Edge Constraint, this could be argued to undermine the plausibility of claiming that deletion of the wh-word or complementiser in such structures serves to avoid violation of the constraint. See fn.9 for some relevant discussion. 